ARTICLE

\title{
Contact-independent killing mediated by a T6SS effector with intrinsic cell-entry properties
}

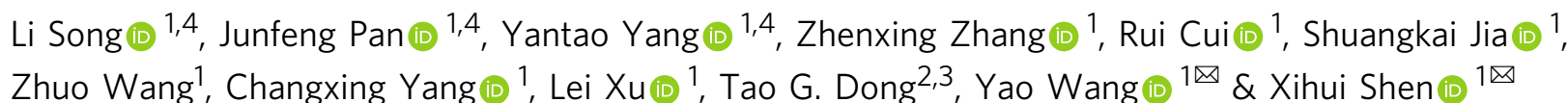

Bacterial type VI secretion systems (T6SSs) inject toxic effectors into adjacent eukaryotic and prokaryotic cells. It is generally thought that this process requires physical contact between the two cells. Here, we provide evidence of contact-independent killing by a T6SS-secreted effector. We show that the pathogen Yersinia pseudotuberculosis uses a T6SS (T6SS-3) to secrete a nuclease effector that kills other bacteria in vitro and facilitates gut colonization in mice. The effector (Tce1) is a small protein that acts as a $\mathrm{Ca}^{2+}$ - and $\mathrm{Mg}^{2+}$-dependent DNase, and its toxicity is inhibited by a cognate immunity protein, Tci1. As expected, T6SS-3 mediates canonical, contact-dependent killing by directly injecting Tce1 into adjacent cells. In addition, T6SS-3 also mediates killing of neighboring cells in the absence of cell-to-cell contact, by secreting Tce1 into the extracellular milieu. Efficient contact-independent entry of Tce1 into target cells requires proteins OmpF and BtuB in the outer membrane of target cells. The discovery of a contact-independent, long-range T6SS toxin delivery provides a new perspective for understanding the physiological roles of T6SS in competition. However, the mechanisms mediating contact-independent uptake of Tce1 by target cells remain unclear.

\footnotetext{
${ }^{1}$ State Key Laboratory of Crop Stress Biology for Arid Areas, Shaanxi Key Laboratory of Agricultural and Environmental Microbiology, College of Life Sciences, Northwest A\&F University, 712100 Yangling, Shaanxi, China. ${ }^{2}$ State Key Laboratory of Microbial Metabolism, Joint International Research Laboratory of Metabolic \& Developmental Sciences, School of Life Sciences and Biotechnology, Shanghai Jiao Tong University, 200240 Shanghai, China. ${ }^{3}$ Department of Ecosystem and Public Health, University of Calgary, Calgary, AB T2N 4Z6, Canada. ${ }^{4}$ These authors contributed equally: Li Song, Junfeng Pan, Yantao Yang. 凶email: wangyao@nwsuaf.edu.cn; xihuishen@nwsuaf.edu.cn
} 
T o survive in complex microbial communities such as the intestinal microbiota, bacteria have evolved various molecular weapons to compete with other species. The classic examples of these weapons are diffusible antimicrobials such as broad-spectrum antibiotics and strain-specific bacteriocins (including microcins, bacteriocins of less than $10 \mathrm{kDa}$ produced through the ribosomal pathway), which can exert long-range inhibitory effects on target cells ${ }^{1-4}$. Some gram-negative bacteria use contact-dependent growth inhibition (CDI), composed by $\mathrm{CdiB}$ translocators and $\mathrm{CdiA}$ toxins, to compete with other bacteria. Similar to bacteriocins and microcins, CDI requires specific outer membrane $(\mathrm{OM})$ receptors on susceptible bacteria for translocation of CdiA toxins into the target cell ${ }^{5,6}$. The type VI secretion system (T6SS) is another contact-dependent weapon in the bacterial competition arsenal but its delivery is generally considered independent of receptors ${ }^{7}$.

T6SSs are widely distributed transmembrane complexes used by many gram-negative bacteria to translocate effectors into adjacent cells in a contact-dependent manner ${ }^{8-11}$. Although some T6SSs are involved in bacterial pathogenesis through delivery of anti-eukaryotic effectors into host cells ${ }^{12-14}$, T6SS is primarily considered an antibacterial weapon to compete against rival bacteria in polymicrobial environments $9,15,16$. The antibacterial function of T6SSs relies on injection of antibacterial effectors that target conserved, essential features of the bacterial cell. Each antibacterial effector is co-expressed with a cognate immunity protein, which protects the producing cells from selfintoxication ${ }^{17,18}$. All contact-dependent T6SS antibacterial weapons characterized to date do not require specific receptors in target cells for delivery of effectors or recognition of prey cells ${ }^{4,7}$. Recently, $\mathrm{Si}$ and colleagues ${ }^{19,20}$ reported a contact-independent role of T6SS in metal acquisition through secretion of metal-scavenging effectors into the extracellular milieu. These findings raise the question of whether T6SS can similarly secrete toxic effectors into the extracellular milieu that recognize and enter target cells, thereby mediating contactindependent killing.

In this work, we report that the Yersinia pseudotuberculosis (Yptb) T6SS-3 mediates a contact-independent killing pathway through secretion of a nuclease effector, Tcel, into extracellular medium. Unlike canonical T6SS effectors, Tce1 can enter prey cells after being secreted into the medium. The Tce1mediated T6SS antibacterial pathway is also required for optimal colonization of the mouse gut by $Y p t b$, whereby it eliminates competing commensals and enteric pathogens. The discovery of a contact-independent T6SS killing pathway adds to current knowledge of the role of T6SS in competition, and opens a new avenue for understanding the ecological consequences of T6SS.

\section{Results}

Identification of novel T6SS effectors. To identify novel T6SS effectors, we searched the Yptb YPIII genome for genes containing the Proline-Alanine-Alanine-aRginine (PAAR) domain, a conserved effector-targeting domain that is linked or adjacent to numerous known T6SS effectors ${ }^{7,21,22}$. A gene locus encoding multiple hypothetical T6SS effector-immunity pairs was identified (YPK_0952-0958, Fig. 1a). Both the first and last open-reading frame (ORF) of this locus contain PAAR domains. The first ORF, YPK_0952, contains a typical PAAR domain at its Nterminus and an S-type pyocin domain at its C-terminus. When VSVG-tagged YPK_0952 was produced in YPIII, the secreted protein was readily detected in the supernatant. However, YPK_0952 secretion was abrogated in the $\Delta 4 c l p V$ mutant, in which all four essential ATPase genes in the four sets of T6SSs were deleted, strongly suggesting that YPK_0952 is a T6SS effector. The secretion of YPK_0952 was dramatically diminished with deletion of $c l p V 3$, but not with deletion of $c l p V 1, c l p V 2$, or clpV4, further indicating that YPK_0952 is a T6SS effector mainly associated with T6SS-3 (Supplementary Fig. 1a). Similarly, we showed that YPK_0954, which does not contain a PAAR domain but is located downstream of YPK_0952, is also a T6SS-3 effector (Fig. $1 \mathrm{~b}$ and Supplementary Fig. $1 \bar{b}$ ).

To confirm the toxic activity of YPK_0954, we performed toxicity assays in Escherichia coli. Expression of YPK_0954, a 67-amino acid (a) protein in E. coli results in significant growth inhibition. This growth inhibition was relieved by co-expression of the immediately downstream gene YPK_0955, which encodes a protein containing the colicin_immun domain in the ypk_0954-ypk_0955 bicistron (Fig. 1c). This result suggests that YPK_0955 is the cognate immunity protein for YPK_0954. We renamed YPK_0954 as T6SS contactindependent antibacterial effector $\underline{1}$ (Tcel) and the immunity protein YPK_0955 as T6SS contact-independent antibacterial immunity 1 (Tci1) for reasons described below.

To assess whether the immunity results from direct proteinprotein interaction, we performed glutathione S-transferase (GST) pull-down and bacterial two-hybrid assays, and the results showed specific interactions between Tcel and Tcil (Fig. 1d, e). These results indicate that Tce1 is a T6SS-3 secreted antibacterial effector and that its toxicity is neutralized by the Tcil immunity protein.

Tcel exhibits $\mathrm{Ca}^{2+}, \mathrm{Mg}^{2+}$-dependent DNase activity. Having demonstrated that Tcel is a T6SS effector, we sought to investigate its biochemical activity. No predictable functional domain could be identified in Tcel using the BLASTP search or other bioinformatics tools. However, further analysis using HHpred $^{23}$ revealed similarity of Tcel with the DNA-binding proteins BldC in Streptomyces coelicolor and CedA in E. coli, implying its potential role as a nuclease toxin. Incubation of chromatographypurified Tce1 (Supplementary Fig. 1c) with $\lambda$-DNA in the same reaction buffer as DNase I led to dramatic DNA degradation in a pattern similar to DNase I (Fig. 1f). The DNase activity of Tce1 critically relies on the co-existence of $\mathrm{Ca}^{2+}$ and $\mathrm{Mg}^{2+}$, and addition of excess EDTA inhibited the activity of both Tcel and DNase I (Fig. 1g and Supplementary Fig. 1d). The circular plasmid pUC19 was also assayed as a substrate (Supplementary Fig. 1e, f), further indicating that Tcel is an endonuclease. Based on random mutant library screening, a mutant that lost toxicity to E. coli (Tce ${ }^{\text {S8A/A16E }}$ ) from approximately 400 candidates was identified (Fig. 1c). The purified mutant protein (Supplementary Fig. 1c) failed to cleave DNA as the Tcel wild-type (WT) protein (Fig. 1h and Supplementary Fig. 1g), clearly demonstrating that the DNase activity of Tcel is not due to contamination. However, Tce1 did not display detectable RNase activity in vitro (Supplementary Fig. 1h, i). Therefore, Tce1 is a $\mathrm{Ca}^{2+}, \mathrm{Mg}^{2+}$-dependent endonuclease that cleaves DNA but not RNA. Consistent with its role as an immunity protein for Tcel, addition of Tcil to the reaction mixture effectively diminished the DNase activity of Tce1 (Supplementary Fig. 1j).

The DNase activity of YPK_0954 was further confirmed in vivo using the terminal deoxynucleotidyl transferase dUTP nick-end labeling (TUNEL) assay and DAPI staining. Although most E. coli cells expressing Tcel exhibited positive TUNEL signals, indicative of DNA fragmentation, E. coli cells expressing Tce1 ${ }^{\mathrm{S} 8 \mathrm{~A} / \mathrm{A} 16 \mathrm{E}}$ and co-expressing Tce1-Tcil, remained unlabeled, similar to the vectoronly control (Fig. 1i). Furthermore, more than $80 \%$ of the E. coli cells expressing Tcel lost DAPI staining after $4 \mathrm{~h}$ induction with IPTG. However, minimal loss of DAPI staining was observed in cells harboring empty vector, expressing Tce $1^{\mathrm{S} 8 \mathrm{~A} / \mathrm{A} 16 \mathrm{E} \text {, or }}$ co-expressing Tce1-Tcil (Fig. 1j and Supplementary Fig. 2). These results establish that Tcel is an actual DNase. 


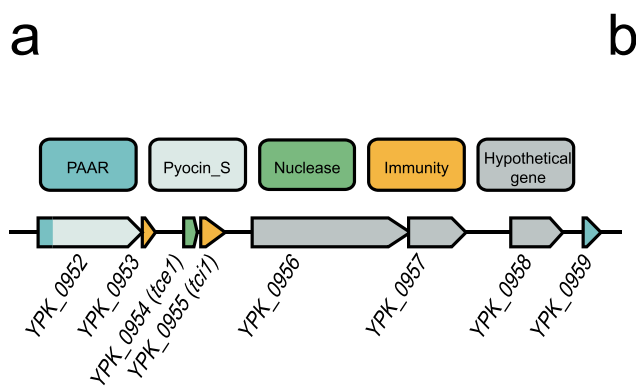

b


Fig. 1 Tce1-Tci1 is a T6SS-3 nuclease effector-immunity pair. a Schematic of genes encoding effector-immunity pairs in YPIII. b Tce1 is a T6SS-3 effector. A plasmid expressing Tce1-VSVG was introduced into indicated Yptb strains. Total cell pellet (Pellet) and secreted proteins in the culture supernatant (Sup) were isolated and probed for the presence of the fusion protein. Cytosolic RNA polymerase (RNAP) was probed as a control. c Growth curves of $E$. coli BL21(DE3) harboring indicated plasmids were obtained by measuring $\mathrm{OD}_{600}$ at 2-h intervals. Data are presented as the mean \pm standard deviation (SD) of three independent experiments. d, e Direct binding between Tce1 and Tci1 was detected using GST pull-down (d) and bacterial two-hybrid (e) assays. d $\mathrm{His}_{6}$-Tci1 was incubated with GST-Tce1, GST, or GST-CheY, and the protein complexes captured on glutathione beads were detected using western blotting. e Interactions between Tce1 and Tci1 were assessed using MacConkey maltose plates (upper) and the $\beta$-galactosidase assay (lower). Error bars indicate \pm SD ( $n=3$ biological replicates), two-sided, unpaired Student's $t$-test was used for these analyses, and $P<0.05$ was considered as significant difference. $\mathbf{f}$ In vitro DNase activity assay showing integrity of $\lambda$ DNA co-incubated with Tce1 or DNase I in DNase I reaction buffer with or without EDTA at $37{ }^{\circ} \mathrm{C}$ for $30 \mathrm{~min}$. Reaction products were analyzed using agarose gel electrophoresis. $\mathbf{g ~ C a}{ }^{2+}, \mathrm{Mg}^{2+}$-dependent DNase activity assay of Tce1. $\lambda$ DNA was incubated with $\mathrm{Tce} 1$ in reaction buffer with or without $\mathrm{Mg}^{2+}$ or $\mathrm{Ca}^{2+}$ at $37^{\circ} \mathrm{C}$ for $30 \mathrm{~min}$. $\mathbf{h}$ DNase activity of the Tce ${ }^{\mathrm{S} 8 \mathrm{~A} / \mathrm{A} 16 \mathrm{E}}$ variant was tested along with Tce 1 and DNase I in the presence of $\mathrm{Ca}^{2+}$ and $\mathrm{Mg}^{2+}$. i Detection of Tce1-induced genomic DNA fragmentation before (left) and $4 \mathrm{~h}$ after (right) IPTG induction in the TUNEL assay. DNA fragmentation was detected based on monitoring of fluorescence intensity (indicated on the $x$-axis) using flow cytometry. The counts resulting from cell sorting are indicated on the $y$-axis. $\mathbf{j}$ Detection of the loss of DNA staining (DAPI) in indicated E. coli cells $4 \mathrm{~h}$ after IPTG induction with fluorescence microscopy (upper) and flow cytometry (lower). The $x$-axis corresponds to $450 \mathrm{H}$ filter reading. Scale bars: $28 \mu \mathrm{m}$.

Tce1 mediates contact-independent T6SS killing. To assess the contribution of the Tce1-Tcil effector-immunity pair to bacterial antagonism, we performed growth competition assays using labeled derivatives of $Y p t b$ co-cultured under conditions promoting cell contact ${ }^{24}$. Notably, the Tce1-Tcil effector-immunity pair apparently underwent a duplication event based on the identification of a highly homologous gene pair $y p k \_2801-y p k$ _2802 in the Yptb genome through a homology search (Supplementary Fig. 3). To simplify the analysis, we generated a deletion mutant lacking $y p k \_2801-y p k \_2802$ as the WT for subsequent experiments. The WT donor exhibited a 3-fold growth advantage in competition with the $\Delta t c e 1 \Delta t c i 1$ recipient. This growth advantage was abrogated by deletion of tce 1 from the donor, or by expression of tcil in the recipient. The Tcel-mediated growth advantage requires a functional T6SS-3, as deletion of $c l p V 3$ $\left(\Delta c l p V 3^{*}, c l p V 3\right.$ deleted in the $\Delta y p k \_2801 \Delta y p k \_2802$ background) completely abolished the growth advantage (Fig. 2a).

Unexpectedly, a strong competitive advantage dependent on Tcel was also observed when cells were grown in liquid medium. As shown in Fig. 2a, donor strains possessing Tcel and a 




C
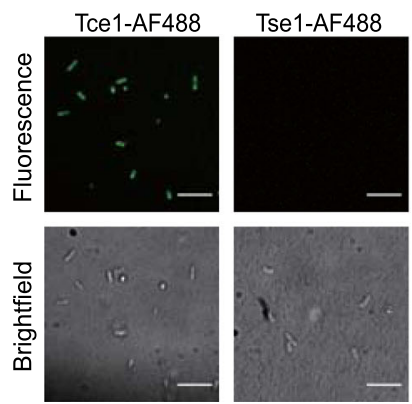

e

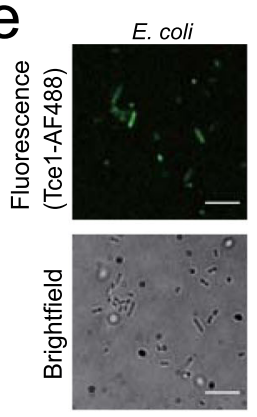

b

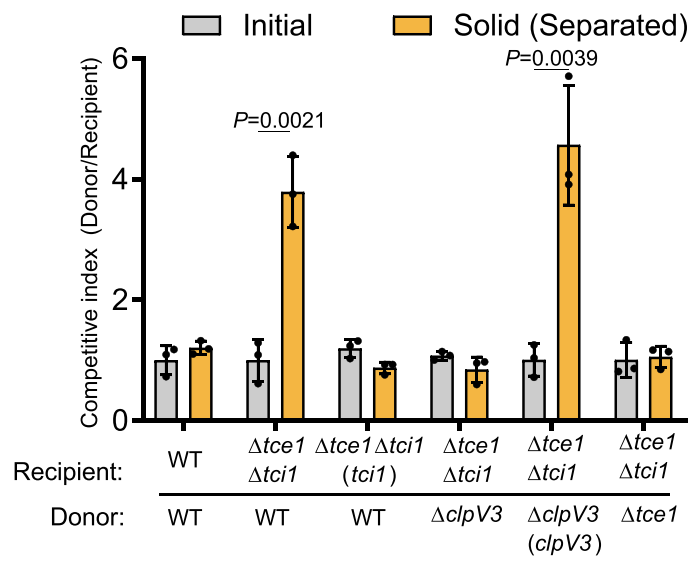

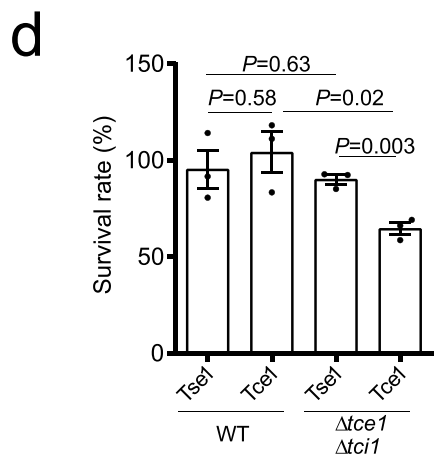
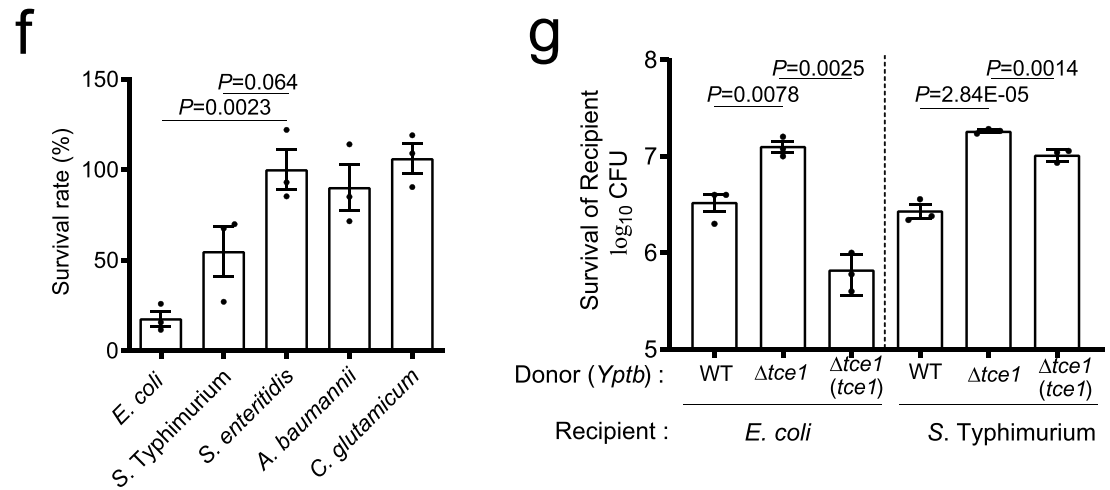

Fig. 2 Tce1 mediates contact-independent T6SS killing. a, b Intra-species growth competition between the indicated Yptb donor and recipient strains. a Donor and recipient strains were mixed 1:1 and then grown for $48 \mathrm{~h}$ on a solid support, or for $24 \mathrm{~h}$ in liquid medium at $26^{\circ} \mathrm{C}$. $\mathbf{b}$ Contact-independent intraspecies growth competition experiments performed by separating donor and recipient cells with a cell-impermeable membrane and grown for $48 \mathrm{~h}$ at $26^{\circ} \mathrm{C}$ on the surface of solid medium. The CFU ratio of the donor and recipient strains was measured based on plate counts. Bars represent the mean donor:recipient CFU ratio from three independent experiments (mean \pm SD), with two-tailed, unpaired Student's $t$-test. Differences were considered statistically significant at $P<0.05$. c Fluorescence labeling of Yptb YPIII with Tce1-AF488 and Tse1-AF488. (scale bars, $20 \mu \mathrm{m}$ ). Quantification of c was shown in Supplementary Fig. 4a. d Toxicity assay of purified Tce1 protein. Stationary-phase cultures of WT Yptb and the $\Delta$ tce1 $\Delta$ tci1 mutant were diluted 40-fold in M9 medium then treated with purified Tce1 or Tse1 $\left(0.01 \mathrm{mg} \mathrm{ml}^{-1}\right)$ for $1 \mathrm{~h}$, and the viability of cells was determined by counting the CFUs after treatment. e Fluorescence labeling of the indicated strains with Tce1-AF488 (scale bars, $20 \mu \mathrm{m}$ ). Quantification of e was shown in Supplementary Fig. $4 \mathrm{~b}$. f Toxicity assay of purified Tce1 protein to the indicated strains. Bacterial strains were diluted in $\mathrm{M} 9$ medium and treated with Tce1 ( $\left.0.1 \mathrm{mg} \mathrm{ml}^{-1}\right)$ for $1 \mathrm{~h}$, and the viability of cells was determined by counting the CFUs after treatment. $\mathbf{g}$ Inter-species growth competition experiments between the indicated Yptb donors and E. coli or S. Typhimurium recipients. Donor and recipient strains were mixed 10:1, then grown for $12 \mathrm{~h}$ in liquid medium at $26^{\circ} \mathrm{C}$. The survival of E. coli or S. Typhimurium cells was quantified by counting CFUs on selective plates. Data in $\mathbf{d}, \mathbf{f}$, and $\mathbf{g}$ are presented as the mean \pm SD of three independent experiments. $P$-values were determined by two-tailed unpaired Student's $t$-test, and differences were acknowledged statistically significant at $P<0.05$.

functional T6SS-3 exhibited significantly increased fitness in competition with $\Delta t c e 1 \Delta t c i 1$ recipients, and expression of $t c i 1$ in the $\Delta t c e 1 \Delta t c i 1$ recipient rescued its competitive fitness (Fig. 2a). Similar results were obtained when the assay was repeated with a cell-impermeable membrane separating the donor and recipient cells on the surface of solid medium (Fig. 2b). Thus, T6SS-3 confers bacteria a contact-independent competitive advantage due to secretion of an antibacterial effector into the extracellular medium, which is distinct from the canonical contact-dependent T6SS mechanism that acts as a conduit to deliver effectors across the envelope of recipient cells ${ }^{25-27}$.

As a nuclease toxin, we assumed that Tcel secreted into the extracellular medium must subsequently enter recipient cells to access its DNA target. To verify this prediction, we performed a 
fluorescence-based assay using Alexa Fluor 488-conjugated Tce1 to probe protein importation ${ }^{28}$. As expected, addition of AF488-Tce1 to WT bacteria cells yielded fluorescent bacteria. By contrast, addition of AF488-conjugated Tse1, a canonical Pseudomonas aeruginosa T6SS toxin that requires the T6SS needle to puncture the target cell for translocation ${ }^{25}$, did not yield fluorescent bacteria (Fig. $2 \mathrm{c}$ and Supplementary Fig. 4a). The contact-independent killing activity of Tcel was also verified by examining its toxicity to target cells in liquid medium. While addition of purified Tcel protein to the liquid medium had little effect on WT survival, it greatly reduced the survival rate of the $\Delta t c e 1 \Delta t c i 1$ mutant, which lacks the immunity protein (Fig. 2d and Supplementary Fig. 5). Conversely, consistent with a previous report ${ }^{25}$, the canonical T6SS toxin Tsel exhibited no toxic effect on both bacterial strains under the same conditions (Fig. 2d). These results suggest that, unlike canonical T6SS effectors, the Tcel effector possesses an intrinsic cell-entry mechanism. Once released into the extracellular medium, this cell-entry mechanism allows Tcel to recognize and enter target cells independent of the T6SS needle.

Through the AF488-based protein importation assay, we found that its cell-entry mechanism also allows Tce1 to specifically enter the cytosol of E. coli and Salmonella Typhimurium, but not that of Salmonella enteritidis, Acinetobacter baumannii, or Corynebacterium glutamicum (Fig. 2e and Supplementary Fig. 4b). In line with these results, exogenous addition of recombinant Tcel protein to the liquid medium substantially reduced the survival rates of $E$. coli and $S$. Typhimurium, but not of $S$. enteritidis, C. glutamicum, or A. baumannii (Fig. 2f). These findings motivated us to further investigate whether Tce1 participates in contact-independent inter-species antagonism. As expected, Tcel significantly contributed to the fitness of Yptb against $E$. coli and $S$. Typhimurium during contact-independent competition assays performed in liquid medium (Fig. 2g).

Together, these results demonstrate that Yptb T6SS-3 follows a non-canonical contact-independent killing mechanism mediated by secretion of Tce1, a unique antibacterial effector with an intrinsic cell-entry mechanism.

Tcel interacts with the $\mathrm{OM}$ receptors BtuB and OmpF. Bacteriocins and microcins are known to recognize specific receptors on sensitive cells to traverse the cell envelope $e^{2,4,29}$. Thus, we hypothesized that Tcel may also interact with membrane receptors to enter target cells. To identify such putative receptors, we performed GST pull-down assays using GST-Tcel coated beads against total cell lysates of Yptb WT cells. Proteins specifically retained by GST-Tce1 were detected using silver staining after sodium dodecyl sulfate-polyacrylamide gel electrophoresis (SDS-PAGE) (Fig. 3a). Mass spectrometric analysis identified several potential Tcel partners: the $80 \mathrm{kDa}$ band as $\mathrm{BtuB}$, a TonB-dependent $\mathrm{OM}$ receptor (YPK_0782; Supplementary Fig. 6); the $40 \mathrm{kDa}$ band as the OmpF porin (YPK_2649; Supplementary Fig. 7); the band around $50 \mathrm{kDa}$ as TolB (YPK_2956), the periplasmic component of the TolABQR transit machinery for group A colicin importation ${ }^{29}$; the $38 \mathrm{kDa}$ band as an OmpA domain transmembrane region-containing protein (YPK_2630); and the $90 \mathrm{kDa}$ band as AcnB (aconitate hydratase 2, YPK_3487). As the involvement of BtuB, OmpF, and TolB in bacteriocin and microcin importation has been well established ${ }^{29-31}$, we focused further investigation on $\mathrm{BtuB}, \mathrm{OmpF}$, and TolB. The specific interactions of Tcel with BtuB, OmpF, and TolB were further supported by bacterial two-hybrid (Fig. $3 \mathrm{~b}$ ) and in vitro binding assays (Fig. 3c-e).

Potential roles of $\mathrm{BtuB}$ and $\mathrm{OmpF}$ in Tcel cell entry. To test potential roles of $\mathrm{BtuB}$ and $\mathrm{OmpF}$ in Tcel cell entry, we performed a fluorescence-based assay using Alexa Fluor 488-conjugated Tce1 to probe its import in vivo ${ }^{28}$. Although addition of Tcel-AF488 to WT $Y p t b$ and $\triangle b t u B$ or $\Delta o m p F$ mutants yielded fluorescent bacteria, the $\triangle b t u B \Delta o m p F$ mutant was not labeled. Labeling of $\triangle b t u B \Delta o m p F$ was weakly but substantially restored through complementation of $o m p F$, and strongly restored through complementation of $b t u B$ (Fig. $4 \mathrm{a}$ and Supplementary Fig. 4c). In addition, we repeated the experiment using GFP labeling instead of AF488. Although exogenous GFP-Tce1 protein could not enter into the cytoplasm of target cells, it specifically labeled bacterial cells expressing ompF or $b t u B$ on the cell surface. In contrast, $\triangle b t u B \Delta o m p F$ was not labeled with GFP-Tcel protein (Fig. $4 \mathrm{~b}$ and Supplementary Fig. $4 \mathrm{~d}$ ). The BtuB/OmpFdependent entry of Tcel into cytosol was further confirmed based on a cell fractionation experiment. As shown in Supplementary Fig. 8, Tcel was detected in the cytosol of WT Yptb but not the $\Delta b t u$ $B \Delta o m p F$ mutant. However, complementation of $b t u B$ partially restored cytosolic Tcel to the WT level.

These observations indicate that $\mathrm{BtuB}$ or $\mathrm{OmpF}$ are required for efficient uptake of Tcel by target cells. Thus, Yptb with mutated BtuB or OmpF can be expected to show natural resistance to Tce1, even when the immunity protein Tcil is not present. We tested this hypothesis by treating various mutants with different concentrations of purified Tcel in M9 medium. As expected, deletion of $b t u B$ or ompF somewhat reduced the sensitivity of the $\Delta t c e 1 \Delta t c i 1$ mutant to exogenously supplied Tce1 protein, while the $\Delta t c e 1 \Delta t c i 1 \Delta b t u B \Delta o m p F$ quadruple mutant was not sensitive to Tcel protein. However, the sensitivity of $\Delta t c e 1 \Delta t c i 1 \Delta b t u B \Delta o m p F$ was weakly restored through complementation of $o m p F$, and strongly restored through complementation of $b t u B$ (Fig. $4 c$ and Supplementary Fig. 5a-c). This also explains why E. coli and S. Typhimurium, which contain highly similar BtuB and OmpF homologs, are sensitive to Tce1 treatment, but $S$. enteritidis, C. glutamicum, and A. baumannii, which do not contain such highly similar BtuB and OmpF homologs, are immune to Tcel treatment (Supplementary Figs. 6 and 7).

Consistent with its crucial role in facilitating bacteriocin transfer across the $\mathrm{OM}^{29,31}$, the tolB deletion mutant was also not sensitive to Tcel treatment, and complementation of $t o l B$ restored the sensitivity to the WT level (Supplementary Fig. 9a). Moreover, while Tce1AF488 labeled the whole cell of WT Yptb and the $\Delta t o l B(t o l B)$ complemented strain, it only weakly labeled the $\Delta t o l B$ mutant on the cell surface (Supplementary Fig. 9b, c), further supporting that TolB plays a role in facilitating Tcel translocation across the OM.

To further investigate whether BtuB and OmpF are involved in Tce1-mediated contact-independent T6SS killing, intra-species competition assays were performed in liquid medium. Although the WT strain strongly inhibited the growth of $\Delta t c e 1 \Delta t c i 1$, it failed to inhibit the growth of the $\Delta t c e 1 \Delta t c i 1 \Delta b t u B \Delta o m p F$ mutant. However, the reduced sensitivity in the $\Delta t c e 1 \Delta t c i 1 \Delta b t u$ $B \Delta o m p F$ mutant was substantially restored by complementation of ompF or $b t u B$ (Fig. $4 \mathrm{~d}$ ). Similar results were obtained when the assay was repeated with a cell-impermeable membrane separating the donor and recipient cells on the surface of solid medium (Supplementary Fig. 10). Similarly, the E. coli $\triangle b t u B \Delta o m p F$ mutant was clearly more tolerant to WT Yptb attack than the WT E. coli in liquid medium (Fig. 4e), further supporting that both $\mathrm{BtuB}$ and OmpF are required for Tce1-mediated contactindependent T6SS killing.

We also examined the roles of BtuB and OmpF in Tce1-mediated contact-dependent T6SS killing on the surface of solid medium. Unexpectedly, the WT Yptb caused stronger inhibition of the growth of the $\Delta t c e 1 \Delta t c i 1 \Delta b t u B \Delta o m p F$ mutant compared with the $\Delta t c e 1 \Delta t c i 1$ mutant (Supplementary Fig. 11a). A potential explanation for this apparent discrepancy is that the membrane of the $\Delta t c e 1 \Delta t c i 1 \Delta b t u$ $B \Delta o m p F$ mutant is vulnerable to T6SS attack. Consistent with this possibility, we found that WT Yptb exhibited stronger inhibition of 


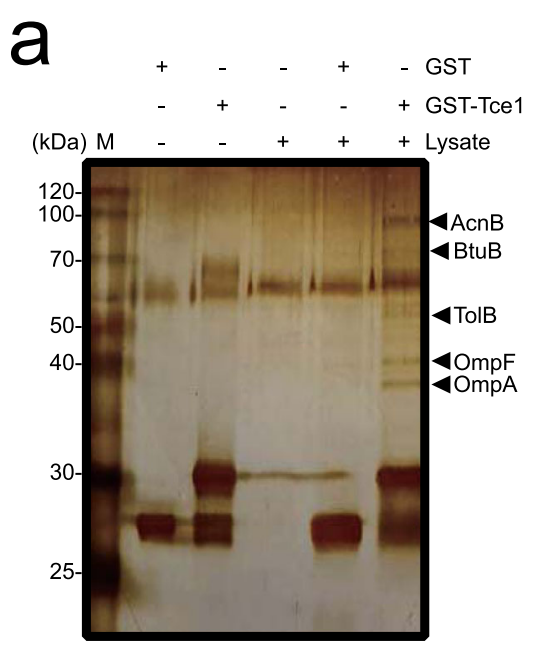

b
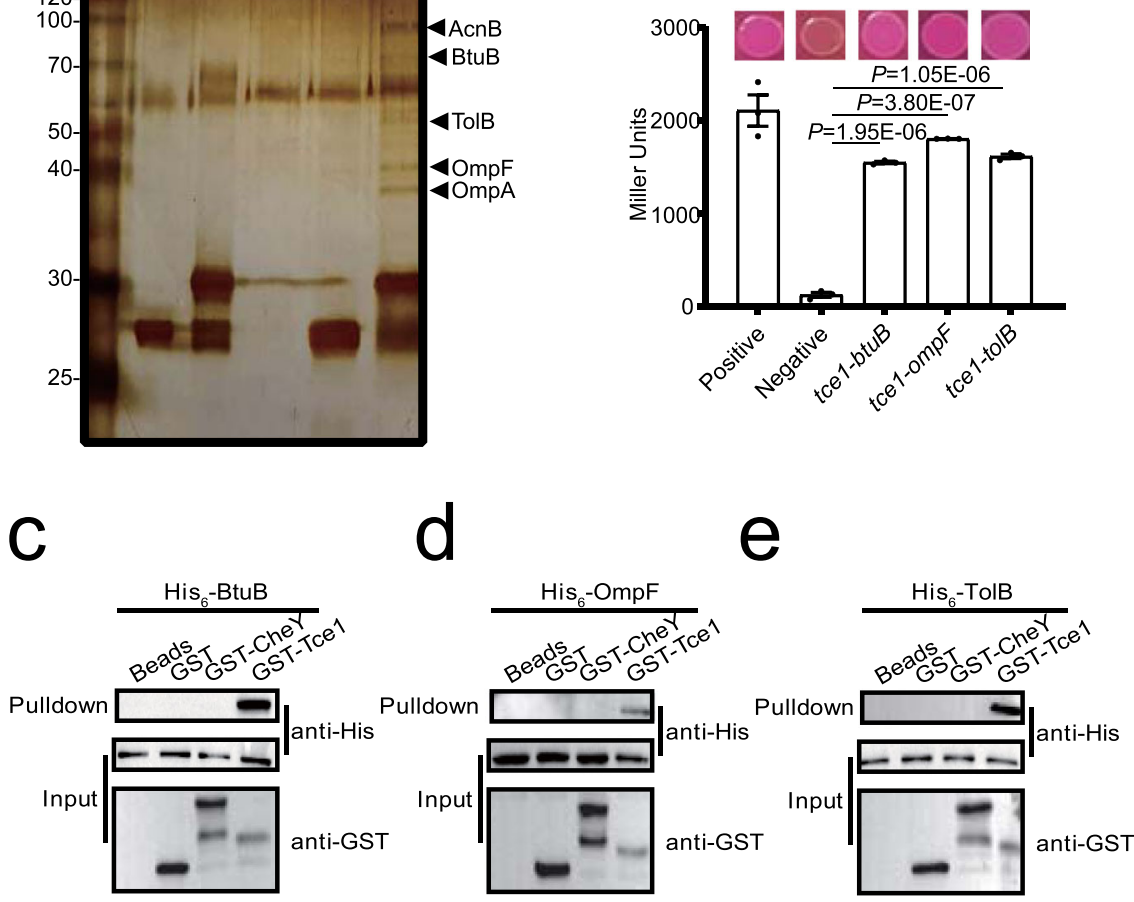

Fig. 3 Tce1 interacts with the outer membrane receptors BtuB and OmpF. a Identification of BtuB and OmpF as the binding partners of Tce1. Total cell lysates of Yptb YPIII were incubated with GST-Bind beads coated with GST-Tce1 or GST. After removing unbound proteins through extensive washing, the retained proteins were resolved through SDS-PAGE followed by silver staining. Protein bands specifically retained by GST-Tce1 were identified through mass spectrometry. $\mathbf{b}$ Interactions between Tce1 and BtuB, OmpF or TolB detected using bacterial two-hybrid assay. Interactions were assessed using MacConkey maltose plates (upper) and the $\beta$-galactosidase assay (lower). Error bars indicate $\pm S D$ ( $n=3$ biological replicates), with two-sided, unpaired Student's t-test. $P<0.001$ was considered as significant differences. c-e Direct binding between Tce1 and BtuB, OmpF or TolB detected using an in vitro GST pull-down assay. His 6 -BtuB (c), His 6 -OmpF (d), or His 6 -TolB (e) was incubated with GST-Tce1, GST, or an irrelevant recombinant protein GST-CheY, and the protein complexes captured on glutathione beads were detected using western blotting. All blots were repeated for at least three times independently with similar results.

the growth of the E. coli $\Delta b t u B \Delta o m p F$ mutant compared to WT E. coli during contact-dependent competition (Supplementary Fig. 11b). Collectively, these results indicate that $\mathrm{BtuB}$ and OmpF are important for contact-independent, but not for contact-dependent, entry of Tcel.

The Tce1-mediated T6SS killing pathway facilitates gut colonization. Some enteric pathogens have been reported to use T6SS to kill symbionts and become established in the mammalian gut $^{32-34}$. To investigate the role of Tcel in facilitating Yptb colonization of the gastrointestinal tract, streptomycin-treated and untreated mice were orally infected with equivalent doses $\left(10^{9}\right.$ colony-forming units, CFUs) of WT Yptb or the $\Delta t c e 1$ and $\Delta c l p V 3^{*}$ mutant. The degree of colonization of the cecum and small intestine of infected mice was determined at 24 and $48 \mathrm{~h}$ post-infection (Fig. 5a, b and Supplementary Fig. 12a, b). Without streptomycin treatment, the CFU level of $\Delta t c e 1$ and $\Delta c l p V 3^{*}$ was significantly lower compared with the WT in both organs. These results demonstrate that the Tce1-mediated T6SS killing pathway is required for colonization of the mouse gut, as it allows for outcompeting of gut commensals. This conclusion was supported by the finding that expression of the tce 1 and T6SS-3 genes was strongly induced during mouse infection compared with growth in YLB medium (Supplementary Fig. 12c). However, pretreatment with antibiotics greatly reduced the observed difference between the WT and $\Delta t c e 1$ in both organs, and between the WT and $\Delta c l p V 3^{*}$ in the small intestine (Fig. 5a, b), indicating that the Tce1-mediated T6SS antibacterial mechanism is not necessary to become established in the gut in the absence of an intact commensal microbial community.

E. coli is known to play important roles in resisting colonization of enteric pathogens in the phylum Proteobacteria ${ }^{35}$. Our finding that the Tce1-mediated T6SS-3 pathway targets $E$. coli in vitro prompted us to further investigate whether it can facilitate $Y p t b$ overcoming colonization resistance in vivo through antagonism of resident gut $E$. coli. Therefore, mice were treated with streptomycin for $24 \mathrm{~h}$ to reduce the number of indigenous commensal bacteria, followed by oral inoculation of mice with $5 \times 10^{8}$ CFUs of $E$. coli DH5a. After $24 \mathrm{~h}$, mice that had been colonized with $E$. coli were challenged with $5 \times 10^{8}$ CFUs of WT $Y p t b$ or $\Delta t c e 1$. At both 24 and $48 \mathrm{~h}$ after infection, the E. coli intestinal load of mice challenged with WT Yptb was significantly lower than that of mice challenged with $\Delta t c e 1$. By contrast, WT Yptb exhibited significantly higher levels of colonization in mice pre-colonized with $E$. coli commensals relative to $\Delta t c e 1$ (Fig. $5 c$, d and Supplementary Fig. 12d, e). These results demonstrated that 
a
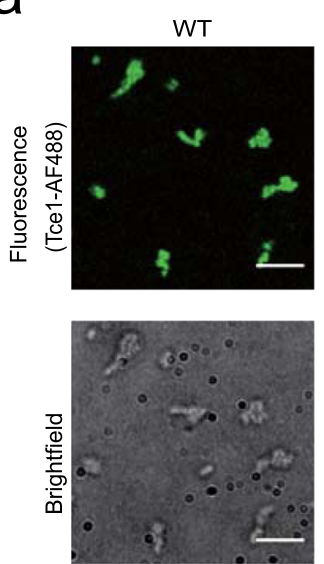

$\Delta o m p F$
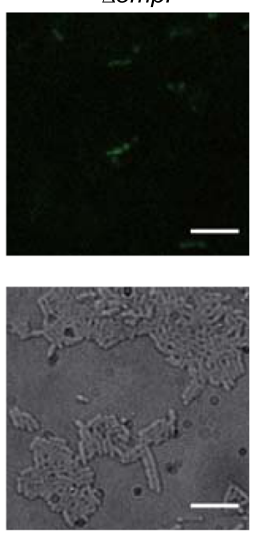

$\Delta b t u B$
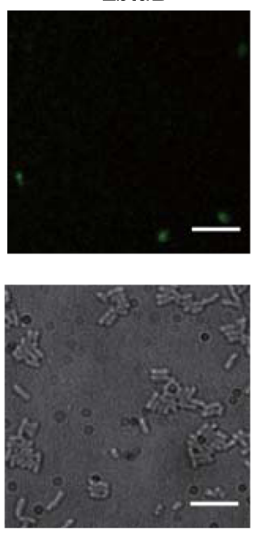

$\triangle o m p F \Delta b t u B$
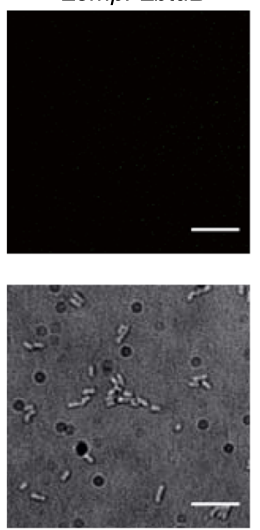

$\triangle o m p F \Delta b t u B$

(btuB)


$\Delta o m p F \Delta b t u B$ (ompF)
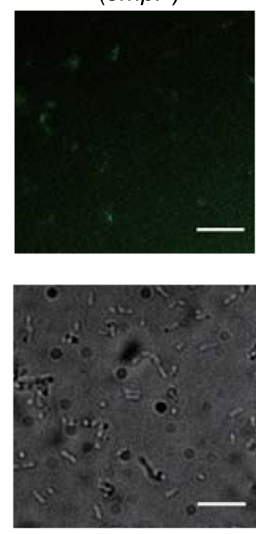

b
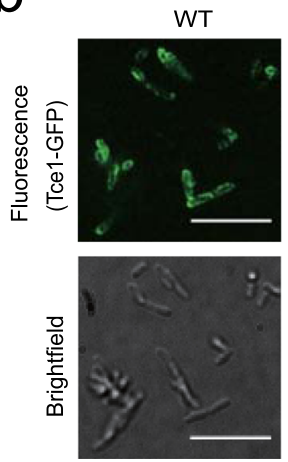

$\triangle o m p F \Delta b t u B$
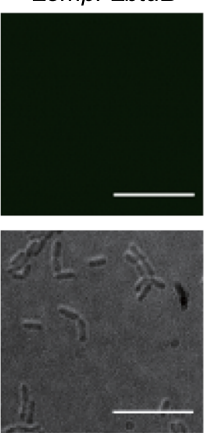
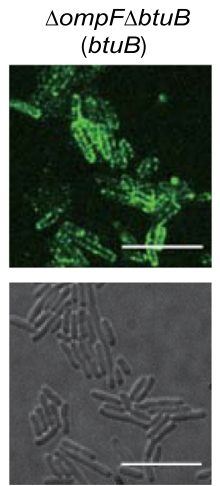

$\Delta o m p F \Delta b t u B$
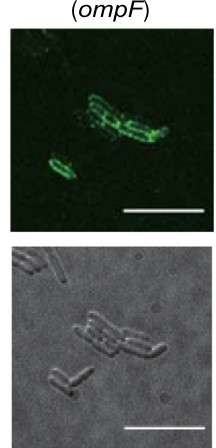

d

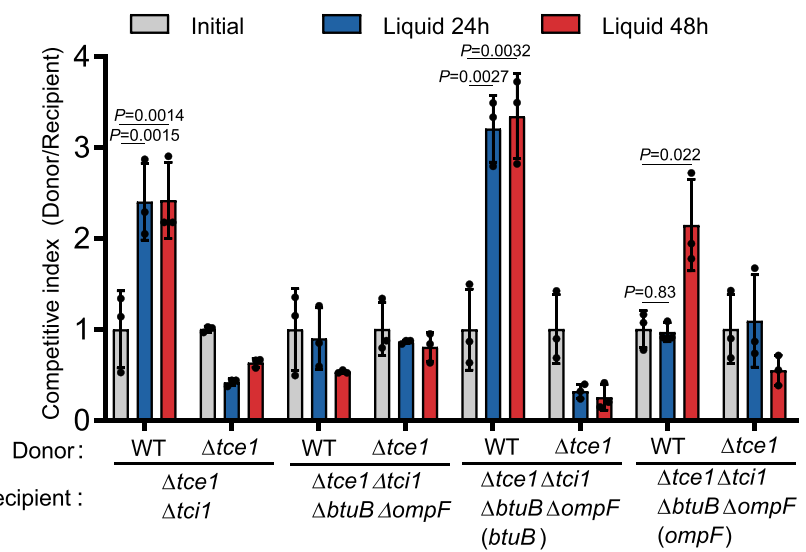

e

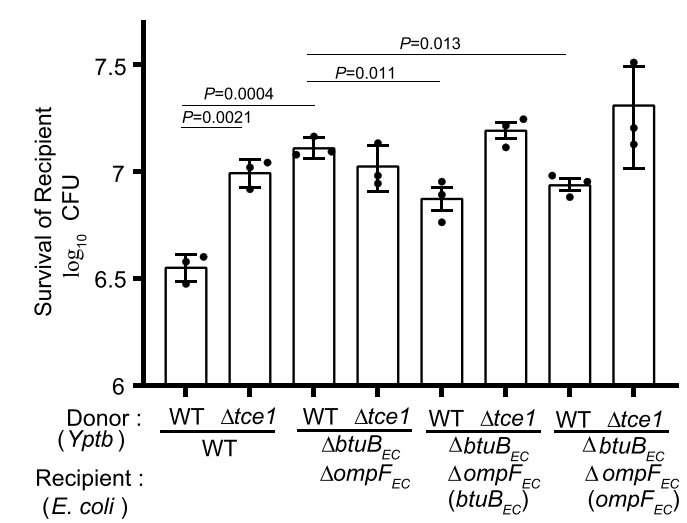

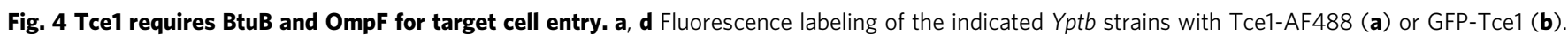
Note that the $\Delta b t u B \Delta o m p F$ mutant shows no labeling, while WT Yptb and complemented strains are labeled in both assays (scale bars, $20 \mu m$ ). Quantification of $\mathbf{a}$ and $\mathbf{b}$ was shown in Supplementary Fig. 4c, d. c Toxicity assays of purified Tce1 protein to Yptb strains. The indicated Yptb strains were diluted 40-fold in M9 medium and treated with purified Tce1 ( $\left.0.1 \mathrm{mg} \mathrm{ml}^{-1}\right)$ for $1 \mathrm{~h}$, and the viability of cells was determined by counting the CFU after treatment. $\mathbf{d}$ Intra-species growth competition experiments between the indicated Yptb donor and recipient strains. Donor and recipient strains were mixed 1:1 and grown for 24 or $48 \mathrm{~h}$ in liquid medium at $26^{\circ} \mathrm{C}$. Bars represent the mean donor:recipient CFU ratios of three independent experiments ( \pm SD). e Inter-species growth competition experiments between the indicated Yptb donor and E. coli DH5 $\alpha$ recipient strains. Donor and recipient strains were mixed 10:1, grown for $12 \mathrm{~h}$ in liquid medium at $26^{\circ} \mathrm{C}$. The survival of $E$. coli cells was quantified by counting CFUs on selective plates. Data are mean $\pm \mathrm{SD}$ from three biological replicates. $P$-values from all data were determined using two-sided, unpaired Student's $t$-test, and significant differences were considered as $P<0.05$.

the Tce1-mediated T6SS killing pathway plays a crucial role in overcoming colonization resistance through antagonism of commensal E. coli.

To gain further insight into the role of Tcel in gut colonization, we investigated whether the antibacterial activity of Tcel is directed against enteric pathogens such as $S$. Typhimurium that share the niche of Yptb. Streptomycin-treated mice were orally co-infected with $5 \times 10^{8}$ CFUs of WT Yptb or $\Delta t c e 1$ or $5 \times 10^{8}$ CFUs of $S$. Typhimurium. The Yptb and $S$. Typhimurium levels were measured in the intestine of co-infected mice at $8 \mathrm{~h}$ postinfection. Again, a dramatic decrease in Salmonella loads were observed in the cecum and small intestine of mice co-infected 
a

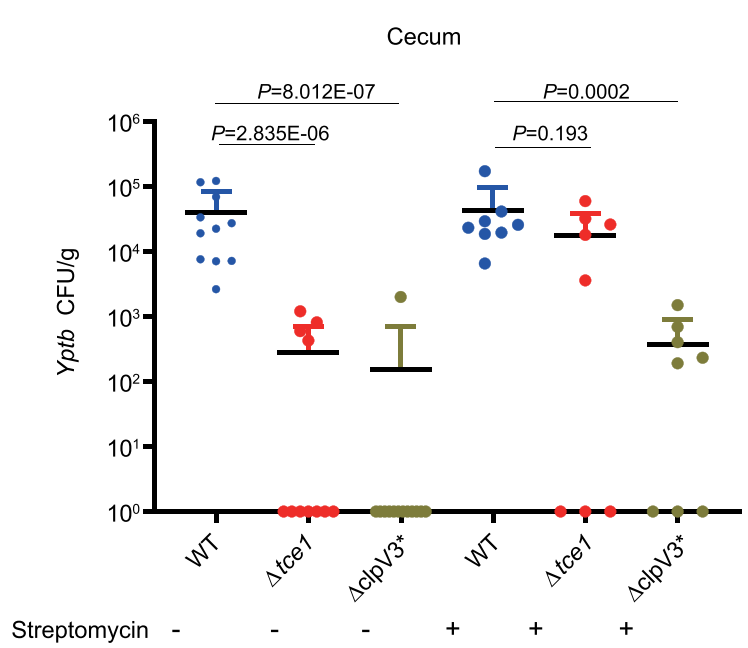

C

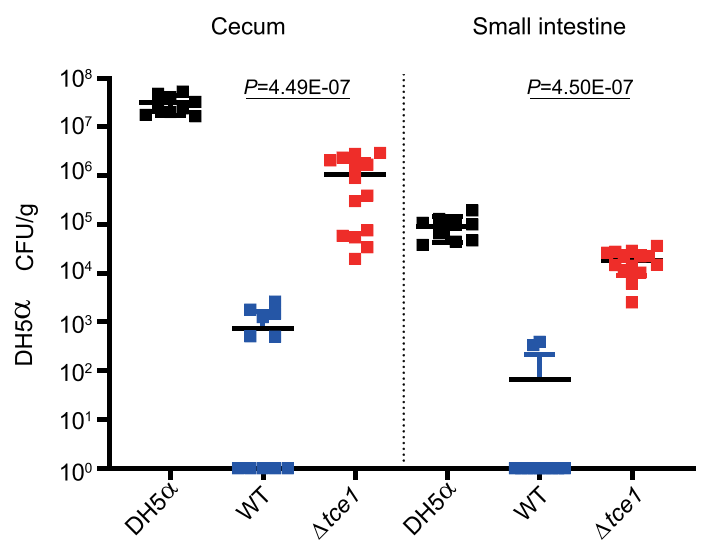

e

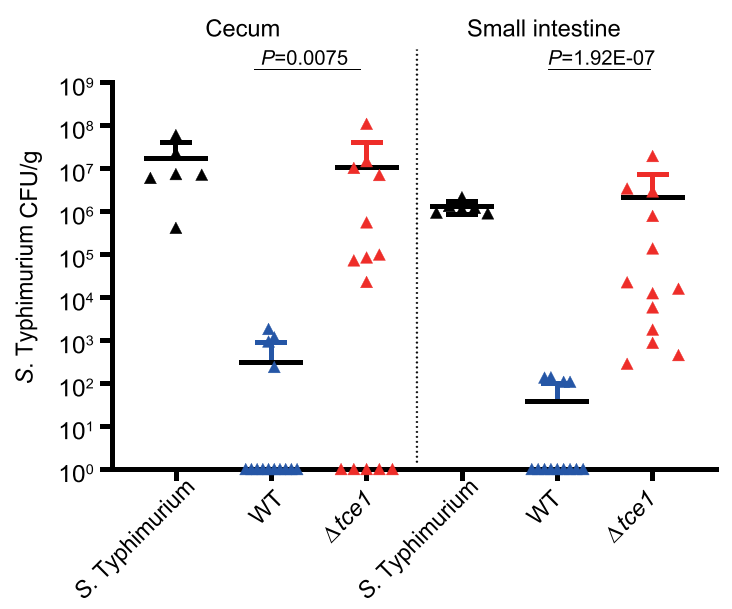

b

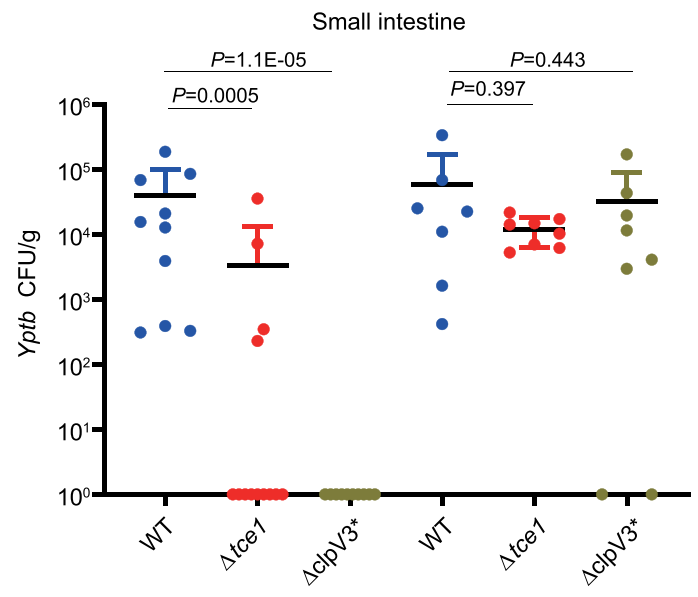

Streptomycin -

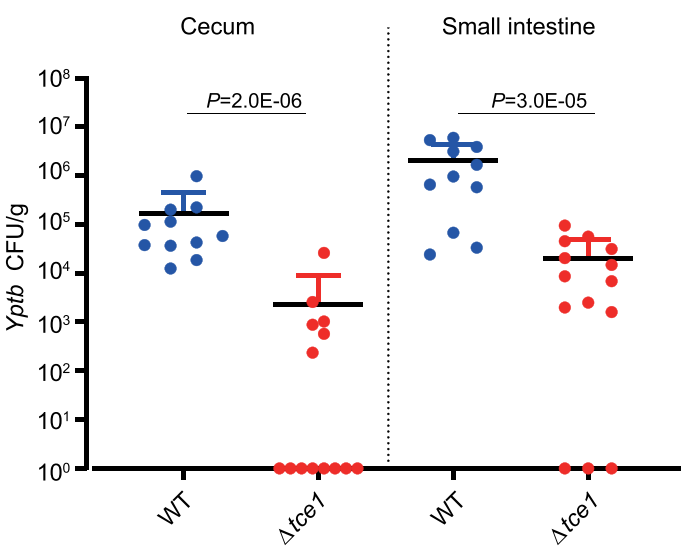

f



Fig. 5 The Tce1-mediated T6SS killing pathway facilitates Yptb colonization of the mouse gut. a, $\mathbf{b}$ Mice with and without streptomycin pre-treatment in a (Strep-: WT $n=11 ; \Delta t c e 1 n=11 ; \Delta c l p V 3^{\star} n=13$ and Strep +: WT $\left.n=8 ; \Delta t c e 1 n=8 ; \Delta c l p V 3^{\star} n=8\right)$ and $\mathbf{b}\left(\right.$ Strep-: WT $n=10 ; \Delta t c e 1 n=13 ; \Delta c l p V 3^{\star} n=$ 10 and Strep + : WT $n=7 ; \Delta t c e 1 n=8 ; \Delta c l p V 3^{\star} n=8$ ) were orally gavaged with $10^{9} \mathrm{CFUs}$ of the indicated Yptb strains. Animals were sacrificed $24 \mathrm{~h}$ after bacterial challenge, and bacterial loads in cecum (a) and small intestine (b) were measured. c, d Streptomycin-treated mice $(n=9-14)$ were colonized with $5 \times 10^{8}$ CFUs of $E$. coli for $24 \mathrm{~h}$ and then challenged with $5 \times 10^{8}$ CFUs of WT Yptb, $\Delta$ tce1 or buffer control (buffer control: $n=9 ;$ WT: $n=11 ; \Delta$ tce1: $n=14$ ). Animals were sacrificed $24 \mathrm{~h}$ after the challenge, and surviving E. coli (c) and Yptb (d) in the cecum and small intestine were counted. PBS mixed with E. coli was used as the negative control. e, $\mathbf{f}$ Streptomycin-treated mice were gavaged with a 1:1 mixture of S. Typhimurium and WT Yptb or $\Delta$ tce1 mutant (buffer control: $n=6$; WT: $n=14 ; \Delta t c e 1: n=14$ ). Animals were sacrificed $8 \mathrm{~h}$ after the challenge, and CFU of S. Typhimurium (e) and Yptb (f) in the cecum and small intestine were counted. PBS mixed with S. Typhimurium was used as the negative control. Each data point represents result from one mouse; error bars represent mean \pm SD of recovered CFUs. Statistical analysis of all experiments was carried out using the two-sided Mann-Whitney test. Differences were determined as significant when $P<0.05$. 
with WT Yptb but not with $\Delta t c e 1$. In contrast, the WT Yptb levels were higher than $\Delta t c e 1$, especially in the cecum (Fig. 5e, f), indicating that the Tce1-mediated T6SS killing pathway plays a crucial role in niche competition by targeting other enteric pathogens.

\section{Discussion}

Here, we report a non-canonical T6SS killing pathway in Yptb in which a small nuclease effector, Tcel, can be translocated into the recipient cell in a contact-independent manner. This is in sharp contrast to the contact-dependent delivery by the T6SSs that directly translocate effectors across the envelope of recipient cells ${ }^{25,26,36}$. Unlike canonical T6SS effectors, Tcel can enter prey cells after being secreted to the extracellular medium (Figs. 2 and 4). Interestingly, T6SS-3 can also deliver Tce1 into target cells in a contact-dependent, receptor-independent manner likely with greater efficiency (Supplementary Fig. 11). This dual mode of translocation makes T6SS-3 an advanced bacterial weapon that functions not only on solid surfaces and in biofilms, but also in liquid culture, and might protect the attacking cells from harm due to retaliatory T6SS attacks ${ }^{10}$ from target cells.

Although we have shown that BtuB and OmpF are important for Tcel cell entry, the underlying translocation mechanisms remain unclear. Further work is needed to test whether Tcel cell entry is mediated by mechanisms similar to those used by some bacteriocins, which use $\mathrm{BtuB}, \mathrm{OmpF}$ or other $\mathrm{OM}$ proteins as receptors ${ }^{28-31,37}$. As numerous T6SS-related toxins have been detected in growth media previously $8,24,38$, it is tempting to speculate that other T6SS toxins may be able to enter target cells in a contact-independent manner.

\section{Methods}

Ethics statement. All mouse experimental procedures were performed in accordance with the Regulations for the Administration of Affairs Concerning Experimental Animals approved by the State Council of People's Republic of China. The protocol was approved by the Animal Welfare and Research Ethics Committee of Northwest A\&F University (protocol number: NWAFUSM2018001). Six-week-old female mice $(B A L B / c)$ were purchased from the central animal laboratory of Xi'An JiaoTong University (Xi'an, China) and kept in a temperature $\left(24 \pm 2{ }^{\circ} \mathrm{C}\right), 50 \pm 10 \%$ humidity, air flow of 35 exchanges and light-controlled room $(12 \mathrm{~h}$ light, $12 \mathrm{~h}$ darkness) with free access to food and water.

Bacteria strains and growth conditions. Bacteria strains and plasmids used in this study are listed in Supplementary Table 1. Yptb strains were grown in YLB (1\% tryptone, $0.5 \%$ yeast extract, $0.5 \% \mathrm{NaCl})$ or $\mathrm{M} 9$ medium $\left(\mathrm{Na}_{2} \mathrm{HPO}_{4}, 6 \mathrm{~g} \mathrm{~L}^{-1}\right.$; $\mathrm{KH}_{2} \mathrm{PO}_{4}, 3 \mathrm{~g} \mathrm{~L}^{-1} ; \mathrm{NaCl}, 0.5 \mathrm{~g} \mathrm{~L}^{-1} ; \mathrm{NH}_{4} \mathrm{Cl}, 1 \mathrm{~g} \mathrm{~L}^{-1} ; \mathrm{MgSO}_{4}, 1 \mathrm{mM} ; \mathrm{CaCl}_{2}, 0.1 \mathrm{mM}$; glucose $0.2 \%$ ) at $26^{\circ} \mathrm{C}$ or $30^{\circ} \mathrm{C}$. E. coli and S. Typhimurium were cultured in LB broth at $37^{\circ} \mathrm{C}$ or $26^{\circ} \mathrm{C}$. Appropriate antibiotics were included in growth medium and their corresponding concentrations are: Ampicillin $\left(100 \mu \mathrm{g} \mathrm{ml}^{-1}\right)$, Nalidixic acid $\left(20 \mu \mathrm{g} \mathrm{ml}^{-1}\right)$, Kanamycin $\left(50 \mu \mathrm{g} \mathrm{ml}^{-1}\right)$, Tetracycline $\left(5 \mu \mathrm{g} \mathrm{ml}^{-1}\right.$ for $Y p t b$ and $15 \mu \mathrm{g} \mathrm{ml}^{-1}$ for E. coli), Gentamicin $\left(20 \mu \mathrm{g} \mathrm{ml}^{-1}\right)$, Chloramphenicol $\left(20 \mu \mathrm{g} \mathrm{ml}^{-1}\right)$.

Plasmid construction. Primers used in this study are listed in Supplementary Table 2. For obtaining expression plasmids, the genes encoding Yptb Tcel (YPK_0954) was amplified by PCR. The DNA fragment was digested and cloned into similarly digested pGEX6p-1 and pET28a vectors, yielding corresponding plasmid derivatives. The expression clones of Tcil (YPK_0955), BtuB (YPK 0782), OmpF (YPK_2649), TolB (YPK_2956) were obtained with the same method. As for the expression plasmid pET28a-tcel-gfp, primers tce1-F-BamHI and tcel-R-EcoRI (TAA) were used to amplify tcel without termination codon TAA, and GFP-FEcoRI and GFP-R-SalI were used to amplify the $g f p$ fragment. Digested fragments were inserted into pET28a to produce pET28a-tce1-gfp. The plasmid pDM4- $\Delta t c e 1$ used to construct the $\Delta t c e 1$ in-frame deletion mutant was made by overlap PCR. Briefly, the 800-bp upstream fragment and the 800-bp downstream fragment of tce 1 were amplified with primer pairs tce1-M1F-BamHI/tce1-M1R and tce1-M2F/ tce1-M2R-SalI, respectively. The upstream and downstream PCR fragments were fused with the primer pair tce1-M1F-BamHI/tcel-M2R-SalI by overlap PCR. The resulting PCR products were digested with BamHI and SalI, and inserted into similar digested suicide plasmid pDM4 to produce pDM4- $\Delta t c e 1$. The knock-out plasmid pDM4- $\Delta t c i 1$, pDM4- $\Delta b t u B$, pDM4- $\Delta o m p F$, pDM4- $\Delta y p k \_2801-2802$ were constructed with similar manners by using primers listed in Supplementary Table 2. To construct plasmids used in bacterial two-hybrid complementation assays, the genes for testing were amplified by PCR from Yptb genomic DNA using appropriate primers. Amplified DNA fragments were digested with appropriate restriction enzymes, and cloned into the corresponding sites of pKT25 and pUT18C vectors, respectively. The plasmid pTargetF1- $\Delta b t u B_{E c}$ was used to construct the $\triangle b t u B_{E c}$ in-frame deletion mutant in E. coli DH5a. To construct pTargetF1- $\triangle b t u B$, upstream and downstream of gene $b t u B_{E c}$ were amplified by PCR using primer pairs B3966-up-F/B3966-up-R and B3966-down-F/B3966down- $R$ respectively. The DNA fragment that code for $b t u B_{E c}$ targeted sgRNA was made by PCR against pTargetF1 using primer pair B3966-g20-F/B3966-g20-R. Overlapping PCR was used to combine these three parts in the order of sgRNAUp-Down and the resulting assembly was ligated to pTargetF1 pre-digested with SpeI/SalI using Gibson Assembly. With a similar method, plasmid pTargetF1$\triangle o m p F_{E c}$ was produced. To complement the $\Delta t c e 1$ mutant, primers tcel-F-BamHI and tce1-R-SalI were employed to amplify the tcel gene fragment from Yptb genomic DNA. The PCR product was digested with BamHI/SalI and ligated into similarly digested pKT100 to produce pKT100-tcel. The complementary plasmids pKT100-tcil, pKT100-btuB, pKT100-tolB, pKT100-ompF, pKT100-btuB $B_{E c}$, and pKT100-omp $F_{E c}$ were similarly constructed. Plasmid pME6032-tce1- vsvg was constructed for protein secretion assay. Briefly, primers tcel-F-EcoRI and tcel-RVSVG-BglII were employed to amplify the tcel gene from Yptb genomic DNA. The PCR product was digested with EcoRI/BglII and inserted into similarly digested pME6032 to generate pME6032-tce1-vsvg. pME6032-ypk_0952-vsvg and pME6032tcil were constructed in the same way. The integrity of the insert in all constructs was confirmed by DNA sequencing.

In-frame deletion and complementation. To construct in-frame deletion mutants, pDM4 derivatives were transformed into Yptb through E. coli S17-1 $\lambda$ pirmediated conjugational mating, achieved by mixing $50 \mu$ l volumes of overnight LB cultures of E. coli S17-1 $\lambda$ pir donor with the Yptb parent. The mixture was spotted onto a non-selective $\mathrm{LB}$ plate and incubated for $16 \mathrm{~h}$ at $30^{\circ} \mathrm{C}$ for mating. Integration of the introduced plasmid into Yptb chromosome by single cross-over was selected on YLB plates containing $20 \mu \mathrm{g} \mathrm{ml}^{-1}$ chloramphenicol and $20 \mu \mathrm{g} \mathrm{ml}^{-1}$ nalidixic acid. The chloramphenicol-resistant colonies were grown overnight in LB broth allowing for a second cross-over to occur. Selection for loss of the genome integrated $s a c B$-containing plasmid was performed on YLB plates containing $20 \%$ sucrose and $20 \mu \mathrm{g} \mathrm{ml}^{-1}$ nalidixic acid. Strains growing on this plate were tested for chloramphenicol sensitivity by parallel spotting on YLB plates containing either chloramphenicol or nalidixic acid. Chloramphenicol-sensitive and sucroseresistant colonies were tested for deletion by PCR and confirmed by DNA sequencing ${ }^{39,40}$. For overexpression or complementation in relevant $Y p t b$ strains, the pME6032 or pKT100 derivatives were transformed into relevant $Y p t b$ strains by electroporation and the expression in $Y p t b$ was induced by adding $1 \mathrm{mM}$ isopropyl $\beta$-D-1-thiogalactopyranoside (IPTG).

Clustered regularly interspaced short palindromic repeats with Cas9 (CRISPRCas9) system was used to construct deletion mutants in E. coli DH5a according to the method described previously ${ }^{41}$, with the spectinomycin resistance gene in the pTargetF plasmid replaced by a chloramphenicol resistance gene (pTargetF1). The pTargetF1 derivatives harboring sg-upstream-downstream were electroporated in E. coli pre-transferred with vector pCas at $30^{\circ} \mathrm{C}$. The mutant colonies were selected on LB plates containing $50 \mu \mathrm{g} \mathrm{ml}^{-1}$ kanamycin and $20 \mu \mathrm{g} \mathrm{ml}^{-1}$ chloramphenicol. The plasmids pTargetF and pCas in the $\Delta b t u B_{E c}$ and $\Delta o m p F_{E c}$ mutant were successively eliminated by IPTG $(1 \mathrm{mM})$ induction at $30^{\circ} \mathrm{C}$ and overnight incubation at $37^{\circ} \mathrm{C}$, respectively ${ }^{42}$. After curing of the pTarget series and pCas plasmids, the deletion mutants were in trans complemented with pKT100 carrying their respective genes.

Overexpression and purification of recombinant proteins. To express and purify $\mathrm{His}_{6}$ and GST-tagged recombinant proteins, pET28a and pGEX6P-1 derivatives were transformed into $E$. coli BL21(DE3) and E. coli XL-1 Blue, respectively. Bacteria were cultured in $5 \mathrm{ml} \mathrm{LB}$ at $37^{\circ} \mathrm{C}$ to reach stationary phase and reinoculated with a ratio of 1:100 into fresh $\mathrm{LB}$, cultivated at $37^{\circ} \mathrm{C}$ until $\mathrm{OD}_{600}=$ 0.40 . Then $0.2-0.5 \mathrm{mM}$ IPTG was added into the growth medium, continue cultivation for another $12 \mathrm{~h}$ at $22^{\circ} \mathrm{C}$ in a rotary shaker with a speed setting of $150 \mathrm{rpm}$. Cells were collected and disrupted by sonification and purified with the His•Bind Ni-NTA resin or GST•Bind Resin (Novagen, Madison, WI), respectively, according to manufacturer's instructions. Purified proteins were dialyzed against PBS (phosphate-buffered saline) at $4{ }^{\circ} \mathrm{C}$ overnight. To get highly purified His-tagged Tcel and Tce ${ }^{\mathrm{S} 8 \mathrm{~A} / \mathrm{A} 16 \mathrm{E}}$ proteins, further processes were adopted after His•Bind $\mathrm{Ni}-$ NTA resin purification. The eluted samples from Ni-NTA were desalted into QA buffer (20 mM Tris-HCl, $0.2 \mathrm{M} \mathrm{NaCl}, 10 \%$ glycerol, $\mathrm{pH}$ 7.5) and loaded onto HiTrap Q HP $1 \mathrm{ml}$ using AKTA Pure 25 chromatography system (GE healthcare, USA). A $20 \mathrm{ml}$ salt concentration gradient from 0.2 to $1 \mathrm{M}$ of $\mathrm{NaCl}$ was performed to separate the protein samples. His-tagged Tcel and Tce $1^{\mathrm{S} 8 \mathrm{~A} / \mathrm{A} 16 \mathrm{E}}$ proteins were eluted at about $0.35 \mathrm{M} \mathrm{NaCl}$ and pooled. The recombinant proteins were over $85 \%$ purity analyzed by SDS-PAGE.

To express and purify outer membrane proteins, E. coli BL21(DE3) that contains the corresponding expression vector was grown in $5 \mathrm{ml} \mathrm{LB}$ at $37^{\circ} \mathrm{C}$ and transferred into $500 \mathrm{ml} \mathrm{LB}$ until $\mathrm{OD}_{600}$ reached $0.4 .0 .3 \mathrm{mM}$ IPTG was added and the growth condition of bacteria was shifted to $22^{\circ} \mathrm{C}$ with shaking at $150 \mathrm{rpm}$. Incubated cells were collected and resuspended in binding buffer $(20 \mathrm{mM}$ Tris- $\mathrm{HCl}$ 
$100 \mathrm{mM}$ glycine, $\mathrm{pH} 8.3$ ) with $6 \mathrm{M}$ urea, and then it was centrifuged again to remove the residual membranes. The supernatant was purified with the His•Bind Ni-NTA resin and eluted with elution buffer. The denatured protein was mixed with refolding buffer $(55 \mathrm{mM}$ Tris- $\mathrm{HCl}, 0.21 \mathrm{mM} \mathrm{NaCl}, 0.88 \mathrm{mM} \mathrm{KCl}, 880 \mathrm{mM} \mathrm{L}$ arginine, $0.5 \% \mathrm{SB}-12, \mathrm{pH} 7.0$ ) with the ratio of $1 / 20$ followed by $4{ }^{\circ} \mathrm{C}$ overnight incubation. The refolded protein was ultrafiltered to increase its purity and concentration and then dialyzed with buffer containing $55 \mathrm{mM}$ Tris- $\mathrm{HCl}$ ( $\mathrm{pH}$ 6.5), $0.21 \mathrm{mM} \mathrm{NaCl}, 10 \mathrm{mM}$ L-arginine, and $0.5 \%$ SB-1220. Protein concentrations were determined by the Bradford assay with BSA (bovine serum albumin) as standard.

GST pull-down assay. To screen for binding partners of Tcel with GST pulldown $^{20,43}, 0.5 \mathrm{mg}$ purified GST-Tcel protein was incubated with $100 \mu \mathrm{l}$ prewashed glutathione beads for $2 \mathrm{~h}$ at $4^{\circ} \mathrm{C}$, then mixed with cleared cell lysates collected from $100 \mathrm{ml}$ of $Y p t b$ culture for another $4 \mathrm{~h}$. After incubation, the beads were collected and washed three times with PBS containing $300 \mathrm{mM} \mathrm{NaCl}$, and three times with PBS containing $500 \mathrm{mM} \mathrm{NaCl}$. Proteins binding on the beads were boiled with SDS sample buffer, resolved by SDS-PAGE and visualized by silver staining (Bio-Rad). Individual protein bands on the gel were excised, digested with trypsin and analyzed by matrix-assisted laser desorption/ionization/mass spectrometry (Voyager-DE STR, Applied Biosystems, Waltham, MA). To analyze protein interactions, purified GST fusion protein was mixed with $6 \times$ His fusion protein in PBS on a rotator for $2 \mathrm{~h}$ at $4{ }^{\circ} \mathrm{C}$, and GST or an irrelevant protein CheY (BTH_II2365 in Burkholderia thailandensis) fused to GST were used as negative controls. After adding $40 \mu \mathrm{l}$ of pre-washed glutathione beads slurry, binding was allowed to proceed for another $2 \mathrm{~h}$ at $4{ }^{\circ} \mathrm{C}$. The beads were then washed five times with TEN buffer ( $100 \mathrm{mM}$ Tris-Cl, $10 \mathrm{mM}$ EDTA, $500 \mathrm{mM} \mathrm{NaCl}, \mathrm{pH} 8.0$ ). Retained proteins were resolved by SDS-PAGE and visualized by western blot.

Bacterial two-hybrid assay. To perform bacterial two-hybrid complementation assays $^{44,45}$, the pKT25 and pUT18C derivatives were co-transformed into E. coli BTH101 and cultured on MacConkey plate (Ampicillin $100 \mu \mathrm{g} \mathrm{ml}^{-1}$, Kanamycin $50 \mu \mathrm{g} \mathrm{ml}^{-1}$, IPTG $1 \mathrm{mM}$ ) at $30^{\circ} \mathrm{C}$. At the same time, the plasmid pKT25-zip/ pUT18C-zip and pKT25/pUT18C were co-transformed into E. coli BTH101 to serve as positive and negative controls, respectively. Interactions were tested using MacConkey medium and a red colony color shows an interaction between proteins, while a white colony color attests the absence of interaction. Efficiencies of interactions between different proteins were quantified by measuring $\beta$ -

galactosidase activities in liquid cultures. In brief, overnight cultures were diluted to $1 \%$ and grown in LB broth with antibiotics at $30^{\circ} \mathrm{C}$ until $\mathrm{OD}_{600}$ reached 1.0 and $\beta$ galactosidase activities were assessed using ONPG as the substrate.

Growth inhibition assay. E. coli BL21(DE3) harboring pET28a empty vector, pET28a-tcel, pET28a-tcel ${ }^{S 8 A / A 16 E}$, and pET28a-tcel-tcil were grown in LB medium. Overnight cultures were adjusted to the same $\mathrm{OD}_{600}$ value and diluted 100 fold into LB broth containing appropriate antibiotics. After incubated at $26^{\circ} \mathrm{C}, 180$ $\mathrm{rpm}$ for $2 \mathrm{~h}$, the expression of recombinant proteins was induced by the addition of $0.5 \mathrm{mM}$ IPTG, and incubated continually under the same condition. The growth of cultures was monitored by measuring $\mathrm{OD}_{600}$ at $2 \mathrm{~h}$ intervals.

Protein toxicity assay. Stationary-phase bacteria strains grown in YLB medium were collected, washed and diluted 40-fold into M9 medium, and treated with purified Tcel and Tse1 toxins $\left(0.005,0.01\right.$, or $\left.0.1 \mathrm{mg} \mathrm{ml}^{-1}\right)$ at $30^{\circ} \mathrm{C}$ with shaking at $100 \mathrm{rpm}$ for $60 \mathrm{~min}$. After treatment, the cultures were serially diluted and plated onto YLB agar plates, and colonies were counted after $36 \mathrm{~h}$ growth at $30^{\circ} \mathrm{C}$. Percentage survival was calculated by dividing the number of CFU of treated cells by the number of CFU of cells without toxin treatment. All these assays were performed in triplicate at least three times.

Protein secretion assay. To perform protein secretion assays ${ }^{46}, Y p t b$ strains were grown in $3 \mathrm{ml} \mathrm{YLB}$ at $30^{\circ} \mathrm{C}$ and transferred into $300 \mathrm{ml} \mathrm{M} 9$ medium with $1 \mathrm{mM}$ IPTG until $\mathrm{OD}_{600}$ reached $0.60-0.65$. Two milliliter of culture solution was collected and the cell pellets were resuspended in SDS-PAGE sample loading buffer. A total of $280 \mathrm{ml}$ cultures was centrifuged at the speed of $5000 \mathrm{rpm}$ for $20 \mathrm{~min}$, and the supernatant was centrifuged for another $50 \mathrm{~min}$ at $9900 \mathrm{rpm}$. The final supernatant was collected and filtered with a $0.22 \mu \mathrm{m}$ pore size filter (Millipore, MA). All the proteins were collected by filtrating through a nitrocellulose filter (BA85, Whatman, Germany) three times. The filter was dissolved in $100 \mu$ l SDS sample buffer for $15 \mathrm{~min}$ at $65^{\circ} \mathrm{C}$ and then boiled for $10 \mathrm{~min}$ to recover the protein present. Protein samples of both total cell pellet and culture supernatant were resolved by SDS-PAGE and detected by western blot analysis. All samples were normalized to the $\mathrm{OD}_{600}$ of the culture and volume used in the preparation. Secretion assays for YPK_0952 were carried out by a similar procedure.

Western blot analysis. Protein samples were resolved by SDS-PAGE and transferred onto polyvinylidene fluoride membranes (Millipore, MA). Then the membrane was blocked in $5 \%(\mathrm{w} / \mathrm{v}) \mathrm{BSA}$ for $8 \mathrm{~h}$ at $4{ }^{\circ} \mathrm{C}$, and incubated with primary antibodies at $4{ }^{\circ} \mathrm{C}$ overnight: anti-VSVG (Santa Cruz biotechnology, catalog no. sc-365019, lot number: B0916), 1:1000; anti-ICDH ${ }^{47}, 1: 6000$; anti-RNAP
(Santa Cruz biotechnology, catalog no. sc-56766, lot number: F2514), 1:400; antiHis (Santa Cruz biotechnology, catalog no. sc-8036, lot number: I1018), 1:500; antiGST (Santa Cruz biotechnology, catalog no. sc-53909, lot number: F2413), 1:500; anti- $\beta$-lactamase (Santa Cruz biotechnology, catalog no. sc-66062, lot number: 8A5.A10),1:1000. The membrane was washed five times in TBST buffer $(50 \mathrm{mM}$ Tris- $\mathrm{HCl}, 150 \mathrm{mM} \mathrm{NaCl}, 0.05 \%$ Tween $20, \mathrm{pH} 7.4$ ), then incubated with 1:5,000 diluted horseradish peroxidase conjugated secondary antibodies (Shanghai Genomics, catalog no. DY60203, lot number: 20614) for $4 \mathrm{~h}$ at $4{ }^{\circ} \mathrm{C}$, and washed further five times with TBST buffer. Signals were detected by using the ECL plus kit (GE Healthcare, Piscataway, NJ) with a Chemiluminescence imager (Tanon 5200Multi, Beijing).

Quantitative real-time PCR (qRT-PCR). Total RNA was isolated from exponentially growing strains using the RNAprep Pure Cell/Bacteria Kit (TIANGEN, Beijing, China) along with the DNase I Kit (Sigma-Aldrich, Taufkirchen, Germany). The concentration of RNA was measured by NanoDrop 2000 (Thermo Fisher Scientific, USA). The TransStart Green qPCR Super-Mix (TransGen Biotech, Beijing, China) and the Bio-Rad CFX96 Real-Time PCR Detection System (Bio-Rad, USA) was used to measure mRNA abundance in each of the samples according to manufacturer's instructions. Primers used in this study are list in Supplementary Table 2 . To normalize the results, the relative abundance of $16 \mathrm{~S}$ rRNA was used as an internal standard.

DNase assay. Purified Tcel protein $(0.016 \mu \mathrm{M})$ was incubated with $\lambda$ DNA $(0.35$ $\mu \mathrm{g}$, Takara, Japan, catalog no. 3010) in the reaction buffer (20 mM MES, $100 \mathrm{mM}$ $\mathrm{NaCl}, 2 \mathrm{mM} \mathrm{CaCl}_{2}, 2 \mathrm{mM} \mathrm{MgCl}$, $\mathrm{pH}$ 6.9). In all, $4 \mathrm{mM}$ EDTA, $2 \mathrm{mM}$ other divalent metal or other component was added in the reaction system as indicated in different experiments. The reaction of DNA hydrolysis was carried out at $37^{\circ} \mathrm{C}$ for $30 \mathrm{~min}$ or indicated time points and the integrity of DNA was analyzed by $0.7 \%$ agarose gel electrophoresis.

RNase assay. Total RNA was extracted from E. coli TG1 and tRNA from E. coli MRE 600 (Roche, Germany, catalog no. 10109541001) was purchased from SigmaAldrich. Two micrograms of RNA was incubated with different concentrations of Tcel in same reaction system as DNase assay at $37^{\circ} \mathrm{C}$ for $30 \mathrm{~min}$. The integrity of RNA was detected by $2 \%$ agarose gel.

Fluorophore labeling of proteins. Fluorophore labeling of proteins was performed as described ${ }^{28}$ with minor modifications. Cysteine residues were present in the $\mathrm{C}$ terminus of both Tcel and Tsel. To prepare the proteins for subsequent labeling reactions, $5 \mathrm{mM}$ DTT was used to reduce the potential disulfide bonds formed by these cysteine residues, and the reactions were conducted at room temperature for $2 \mathrm{~h}$. After the reduction of disulfide bonds, DTT is removed by dialysis in $20 \mathrm{mM}$ potassium phosphate $(\mathrm{pH} 7.0)$ and $500 \mathrm{mM} \mathrm{NaCl}$. Labeling reactions were carried out by adding $10 \mathrm{mM}$ maleimide fluorophores (Thermo Fisher Scientific, USA catalog no. A10254) dissolved in dimethyl sulfoxide into reduced protein at a molar ratio of 5:1 (maleimide: protein), followed by $4{ }^{\circ} \mathrm{C}$ incubation in the dark overnight The reaction was quenched by adding $2 \mathrm{mM}$ DTT and dialyzed into $2 \mathrm{~L}$ of $20 \mathrm{mM}$ potassium phosphate $(\mathrm{pH} 7.0)$ and $500 \mathrm{mM} \mathrm{NaCl}$ overnight at $4{ }^{\circ} \mathrm{C}$.

Fluorescent labeling of live bacteria. Fluorescent labeling of live bacterial strains was performed according to described methods ${ }^{28}$ with some modifications. Briefly, cultures at $\mathrm{OD}_{600}=0.7$ were centrifuged and resuspended in M9-glucose containing $1 \mu \mathrm{M}$ fluorophore-conjugated protein, incubated in the dark at room temperature for $30 \mathrm{~min}$. The cells were washed five times to remove the free label and resuspended in $100 \mu \mathrm{l}$ volume in M9-glucose. Ten microliters of the cell suspension was dispensed onto $1 \%(\mathrm{w} / \mathrm{v})$ agarose pads on a microscope slide before sealing with a clean glass coverslip. The result was obtained by high-speed rotary disc type fluorescence confocal microscope (Andor Revolution-XD, UK).

TUNEL (terminal deoxynucleotidyl transferase dUTP nick-end labeling) and flow cytometry analysis. Overnight culture of E. coli BL21(DE3) containing the pET28a plasmid or its derivatives expressing Tcel alone (pET28a-tce1) or Tce1Tcil together (pET28a-tce1-tcil) were diluted 100-fold into LB broth and incubated at $26^{\circ} \mathrm{C}$ with $180 \mathrm{rpm}$ shaking. After incubated at $26^{\circ} \mathrm{C}$ for $2 \mathrm{~h}$, the expression of toxin and immunity genes was induced by addition of $0.5 \mathrm{mM}$ IPTG and continue cultivation for $4 \mathrm{~h}$ at $26^{\circ} \mathrm{C}$. Collected cells were washed with PBS, fixed, incubated for $5 \mathrm{~min}$ in PBS with $0.3 \%$ Triton X-100 and stained using Onestep TUNEL cell apoptosis detection kit (Beyotime Biotechnology, China). When genomic DNA breaks, exposed 3'-OH can be labeled with green fluorescent probe FITC catalyzed by terminal deoxynucleotidyl transferase (TdT), which can be detected by flow cytometry (Beckman, CytoFLEX). Ten-thousand cells were gathered for each sample and analyzed by FlowJo_V10 ${ }^{48}$.

DAPI staining and flow cytometry analysis. To perform DAPI staining and flow cytometry analysis ${ }^{49}$, overnight culture of $E$. coli BL21(DE3) containing the pET28a plasmid or its derivatives expressing Tcel alone (pET28a-tce1) or Tcel-Tcil together (pET28a-tce1-tcil) were diluted 100-fold into LB broth and incubated at 
$26^{\circ} \mathrm{C}$ with $180 \mathrm{rpm}$ shaking. After incubated at $26^{\circ} \mathrm{C}$ for $2 \mathrm{~h}$, the expression of toxin and immunity genes was induced by addition of $0.5 \mathrm{mM}$ IPTG and continue cultivation for $4 \mathrm{~h}$ at $26^{\circ} \mathrm{C}$. Collected cells were washed with PBS, fixed, incubated for $5 \mathrm{~min}$ in PBS with $0.3 \%$ Triton X-100 stained using $10 \mu \mathrm{g} \mathrm{ml}^{-1}$ DAPI for 30 min at $37^{\circ} \mathrm{C}$ (Solarbio, China), then washed three times with PBS and detected by fluorescence microscope (Andor Revolution-XD, Britain) or flow cytometry (Beckman, CytoFLEX). Twenty-thousand cells were gathered for each sample and analyzed by FlowJo_V10.

Subcellular fractionation. To perform subcellular fractionation ${ }^{50}, 2 \mathrm{ml}$ overnight grown Yptb culture $\left(\mathrm{OD}_{600} 1.0\right)$ was collected, washed, and incubated in $2 \mathrm{ml} \mathrm{M} 9$ containing $0.05 \mathrm{mg}$ Tce 1 at $30^{\circ} \mathrm{C}$ for $60 \mathrm{~min}$. Tcel-treated bacterial cells were washed with PBS to remove extracellular Tcel protein, and incubated into $285 \mu \mathrm{l}$ sucrose buffer (20 mM PBS, pH 7.4, 20\% sucrose, $2.5 \mathrm{mM}$ EDTA) for $20 \mathrm{~min}$ at room temperature. After that, $285 \mu$ lice-cold $0.5 \mathrm{mM} \mathrm{MgCl}_{2}$ was added and incubated for $5 \mathrm{~min}$ with gentle agitation. The suspension was centrifuged a $7000 \times g$ for $20 \mathrm{~min}$ at $4{ }^{\circ} \mathrm{C}$ to collect the supernatant containing periplasmic proteins (Peri). The pellet was resuspended in SDS-loading buffer and defined as cytoplasmic (Cyto). All the samples were examined by SDS-PAGE and western blotting analysis.

Construction of mutant library by epPCR. Error-prone PCR (epPCR) was conducted on plasmid pET28a-tce1 by using the QuickMutation ${ }^{\mathrm{TM}}$ Random Mutagenesis Kit (Beyotime Biotechnology, China) with primers tce1-F-BamHI and tce1$\mathrm{R}$-SalI according to manufacturer's instructions. The epPCR program was as follows: $94^{\circ} \mathrm{C}$ for $3 \mathrm{~min}, 30$ cycles of $30 \mathrm{~s}$ at $94^{\circ} \mathrm{C}, 30 \mathrm{~s}$ at $55^{\circ} \mathrm{C}$, and $30 \mathrm{~s}$ at $72{ }^{\circ} \mathrm{C}$, followed by $10 \mathrm{~min}$ at $72^{\circ} \mathrm{C}$ final extension. The PCR products were gel-purified, digested with BamHI and SalI, and cloned into similarly digested pET28a. The ligation mixture was transformed into BL21(DE3). Transformants lost toxicity were screened in LB medium containing $0.5 \mathrm{mM}$ IPTG and were further verified by cloning the mutated alleles of $t c e 1$ into new vector ${ }^{51}$. The mutations were identified by DNA sequencing analysis.

Intra-species and inter-species competition in vitro. For intra-species competition assays ${ }^{24}$, overnight grown strains were washed and adjusted to $\mathrm{OD}_{600}$ of 1.0 with M9 medium before mixing for competition. The initial donor-to-recipient ratio was $1: 1$ and the co-cultures were either spotted onto a $0.22 \mu \mathrm{m}$ nitrocellulose membrane (Nalgene) placed on M9 agar plates at $26^{\circ} \mathrm{C}$ for $48 \mathrm{~h}$ (for contactdependent competition), or inoculated into $2 \mathrm{ml} \mathrm{M} 9$ medium at $26^{\circ} \mathrm{C}$ with shaking for $24 \mathrm{~h}$ or $48 \mathrm{~h}$ (for contact-independent competition in liquid medium). For contact-independent competition performed on a solid surface, $5 \mu \mathrm{l}$ of the recipient strain was spotted on $0.22 \mu \mathrm{m}$ nitrocellulose membrane on M9 agar plates. After the bacterial solution was dried, another $0.22 \mu \mathrm{m}$ nitrocellulose membrane was put on it and $5 \mu$ of the donor strain was spotted on the same place of the second membrane and incubated at $26^{\circ} \mathrm{C}$ for $48 \mathrm{~h}$. The donor and recipient strains were labeled with pKT100 $\left(\mathrm{Km}^{\mathrm{R}}\right)$ or pACYC184 $\left(\mathrm{Cm}^{\mathrm{R}}\right)$, respectively, to facilitate screening on YLB plates. At indicated time points after the competition, the CFU ratio of the donor and recipient strains was measured by plate counts. Data from all competitions were analyzed using the Student's $t$-test, and the results shown represent the mean of one representative assay performed in triplicate.

For inter-species competition assays, overnight grown Yptb strains harboring pKT100 $\left(\mathrm{Km}^{\mathrm{R}}\right)$ and E. coli $(\mathrm{DH} 5 \alpha)$ or S. Typhimurium strains containing pBBRMCS5-GFP $\left(\mathrm{Gm}^{\mathrm{R}}\right)$ or pME6032 $\left(\mathrm{Tet}^{\mathrm{R}}\right)$ (gentamycin or tetracycline resistance) were washed three times with $\mathrm{M} 9$ medium, and adjusted to $\mathrm{OD}_{600}=$ 1.0. Yptb strains diluted to 10 -folds and target strains attenuated to 100 -folds were mixed together so that the ratio of donor and recipient was 10 to 1 in M9 liquid, incubated at $26^{\circ} \mathrm{C}$ with the speed of $120 \mathrm{rpm}$. After the competition, mixtures were serially diluted, counted on LB plates containing appropriate antibiotics, and the final CFU was determined.

Murine infection and in vivo competition assays. Female 6-week-old BALB/c mice were adapted in the lab for 3 days and orally gavaged with $10^{9}$ CFUs of the indicated $Y p t b$ strains labeled by pKT100 $\left(\mathrm{Km}^{\mathrm{R}}\right)$ and monitored for 24 or $48 \mathrm{~h}$. When indicated, mice were orally gavaged with streptomycin $\left(100 \mu \mathrm{lof} 200 \mathrm{mg} \mathrm{ml}^{-1}\right.$ solution) $24 \mathrm{~h}$ prior to $Y p t b$ infection. At the end of the experiment animals were sacrificed, and the cecum and small intestine tissue were ground, plated on selective YLB antibiotic plates for CFU enumeration.

For competition assays between $Y p t b$ and E. coli in mouse gut, female 6-weekold BALB/c mice were orally gavaged with streptomycin $\left(100 \mu \mathrm{l} \mathrm{of} 200 \mathrm{mg} \mathrm{m}^{-1}\right.$ solution) on day 1 . On day $2,5 \times 10^{8} \mathrm{CFU}$ E. coli DH5a containing GFP was gavaged, and on day $3,5 \times 10^{8} \mathrm{CFU}$ of $Y p t b$ strains was orally gavaged. After $24 \mathrm{~h}$ on day 4 and $48 \mathrm{~h}$ on day 5 , mice were sacrificed and cecum and small intestine tissue were separated, serial diluted, spread on YLB (nalidixic acid, for selection of $Y p t b$ ) or LB (gentamicin, for selection of E. coli) plates for CFU enumeration.

For competition assays between $Y p t b$ and $S$. Typhimurium, due to the difficulty of detecting $S$. Typhimurium in cecum tissues after $12 \mathrm{~h}$, mice pre-treated with streptomycin for 2 days were orally gavaged with a mixture of equal bacterial count $\left(5 \times 10^{8} \mathrm{CFU}\right)$ of $Y p t b$ and $S$. Typhimurium containing pME6032. Eight hours later, mice were sacrificed, cecum and small intestine tissue were separated, serial diluted, and spread on YLB (nalidixic acid, for selection of Yptb) or XLT4 $4^{52}$ (tetracycline, for selection of $S$. Typhimurium) plates for CFU enumeration.

Statistics and reproducibility. Statistical analyses were performed using GraphPad Prism Software (GraphPad Prism 7.00). All experiments were performed in at least three independent replicates. Statistical analyses of colonization assay in mice, intra-species and inter-species competition assay in mice were analyzed using twosided Mann-Whitney test. All other experiments were analyzed using unpaired, two-tailed Student's $t$-test. Statistical significance is determined when $P<0.05$. All gels, blots, and micrographs were repeated for at least three times independently with similar results.

Reporting summary. Further information on research design is available in the Nature Research Reporting Summary linked to this article.

\section{Data availability}

The protein sequences are available from the Uniprot database (http://www.uniprot.org/). Other data supporting the findings of this study are included in the article and its Supplementary Information files, or from the corresponding authors upon request. Source data are provided with this paper.

Received: 25 August 2020; Accepted: 10 December 2020; Published online: 18 January 2021

\section{References}

1. Baquero, F., Lanza, V. F., Baquero, M. R., Del Campo, R. \& Bravo-Vazquez, D A. Microcins in Enterobacteriaceae: peptide antimicrobials in the eco-active intestinal chemosphere. Front. Microbiol. 10, 2261 (2019).

2. Mathavan, I. \& Beis, K. The role of bacterial membrane proteins in the internalization of microcin MccJ25 and MccB17. Biochem. Soc. Trans 40, 1539-1543 (2012).

3. Garcia-Bayona, L. \& Comstock, L. E. Bacterial antagonism in host-associated microbial communities. Science 361, eaat2456 (2018).

4. Chassaing, B. \& Cascales, E. Antibacterial weapons: targeted destruction in the microbiota. Trends Microbiol 26, 329-338 (2018).

5. Aoki, S. K. et al. A widespread family of polymorphic contact-dependent toxin delivery systems in bacteria. Nature 468, 439-442 (2010).

6. Ruhe, Z. C. et al. Programmed secretion arrest and receptor-triggered toxin export during antibacterial contact-dependent growth inhibition. Cell 175, 921-933.e14 (2018).

7. Whitney, J. C. et al. An interbacterial $\mathrm{NAD}(\mathrm{P})(+)$ glycohydrolase toxin requires elongation factor Tu for delivery to target cells. Cell 163, 607-619 (2015).

8. Trunk, K. et al. The type VI secretion system deploys antifungal effectors against microbial competitors. Nat. Microbiol. 3, 920-931 (2018).

9. Cianfanelli, F. R., Monlezun, L. \& Coulthurst, S. J. Aim, load, fire: the type VI secretion system, a bacterial nanoweapon. Trends Microbiol 24, 51-62 (2016).

10. Basler, M., Ho, B. T. \& Mekalanos, J. J. Tit-for-tat: type VI secretion system counterattack during bacterial cell-cell interactions. Cell 152, 884-894 (2013).

11. Wang, J. et al. Cryo-EM structure of the extended type VI secretion system sheath-tube complex. Nat. Microbiol. 2, 1507-1512 (2017).

12. Aubert, D. F. et al. A Burkholderia type VI effector deamidates Rho GTPases to activate the pyrin inflammasome and trigger inflammation. Cell Host Microbe 19, 664-674 (2016)

13. Chen, H. et al. The bacterial T6SS effector EvpP prevents NLRP3 inflammasome activation by inhibiting the $\mathrm{Ca}(2+)$-dependent MAPK-Jnk pathway. Cell Host Microbe 21, 47-58 (2017).

14. Ledvina, H. E. et al. A phosphatidylinositol 3-kinase effector alters phagosomal maturation to promote intracellular growth of Francisella. Cell Host Microbe 24, 285-295.e8 (2018).

15. LaCourse, K. D. et al. Conditional toxicity and synergy drive diversity among antibacterial effectors. Nat. Microbiol. 3, 440-446 (2018).

16. Hachani, A., Wood, T. E. \& Filloux, A. Type VI secretion and anti-host effectors. Curr. Opin. Microbiol. 29, 81-93 (2016).

17. Russell, A. B., Peterson, S. B. \& Mougous, J. D. Type VI secretion system effectors: poisons with a purpose. Nat. Rev. Microbiol. 12, 137-148 (2014).

18. Ho, B. T., Dong, T. G. \& Mekalanos, J. J. A view to a kill: the bacterial type VI secretion system. Cell Host Microbe 15, 9-21 (2014).

19. Si, M. et al. The type VI secretion system engages a redox-regulated dualfunctional heme transporter for zinc acquisition. Cell Rep 20, 949-959 (2017).

20. Si, M. et al. Manganese scavenging and oxidative stress response mediated by type VI secretion system in Burkholderia thailandensis. Proc. Natl Acad. Sci. USA 114, E2233-E2242 (2017). 
21. Ting, S. Y. et al. Bifunctional immunity proteins protect bacteria against FtsZtargeting ADP-ribosylating toxins. Cell 175, 1380-1392.e14 (2018).

22. Burkinshaw, B. J. et al. A type VI secretion system effector delivery mechanism dependent on PAAR and a chaperone-co-chaperone complex. Nat. Microbiol. 3, 632-640 (2018).

23. Zimmermann, L. et al. A completely reimplemented MPI bioinformatics toolkit with a new HHpred server at its core. J. Mol. Biol. 430, 2237-2243 (2018).

24. Hood, R. D. et al. A type VI secretion system of Pseudomonas aeruginosa targets a toxin to bacteria. Cell Host Microbe 7, 25-37 (2010).

25. Russell, A. B. et al. Type VI secretion delivers bacteriolytic effectors to target cells. Nature 475, 343-347 (2011).

26. MacIntyre, D. L., Miyata, S. T., Kitaoka, M. \& Pukatzki, S. The Vibrio cholerae type VI secretion system displays antimicrobial properties. Proc. Natl Acad. Sci. USA 107, 19520-19524 (2010).

27. Quentin, D. et al. Mechanism of loading and translocation of type VI secretion system effector Tse6. Nat. Microbiol. 3, 1142-1152 (2018).

28. White, P. et al. Exploitation of an iron transporter for bacterial protein antibiotic import. Proc. Natl Acad. Sci. USA 114, 12051-12056 (2017).

29. Cascales, E. et al. Colicin biology. Microbiol. Mol. Biol. Rev. 71, 158-229 (2007).

30. Housden, N. G. et al. Intrinsically disordered protein threads through the bacterial outer-membrane porin OmpF. Science 340, 1570-1574 (2013).

31. Jakes, K. S. \& Cramer, W. A. Border crossings: colicins and transporters. Annu. Rev. Genet. 46, 209-231 (2012).

32. Sana, T. G. et al. Salmonella Typhimurium utilizes a T6SS-mediated antibacterial weapon to establish in the host gut. Proc. Natl Acad. Sci. USA 113, E5044-E5051 (2016).

33. Anderson, M. C., Vonaesch, P., Saffarian, A., Marteyn, B. S. \& Sansonetti, P. J. Shigella sonnei encodes a functional T6SS used for interbacterial competition and niche occupancy. Cell Host Microbe 21, 769-776.e3 (2017).

34. Zhao, W., Caro, F., Robins, W. \& Mekalanos, J. J. Antagonism toward the intestinal microbiota and its effect on Vibrio cholerae virulence. Science 359, 210-213 (2018).

35. Coyne, M. J. \& Comstock, L. E. Type VI Secretion systems and the gut microbiota. Microbiol. Spectr 7, 10.1128 (2019).

36. Mueller, E. A. \& Levin, P. A. Evolving to end a toxic relationship: ADP ribosylation in interbacterial warfare. Cell 175, 1182-1184 (2018).

37. Rebuffat, S. Microcins in action: amazing defence strategies of Enterobacteria. Biochem. Soc. Trans 40, 1456-1462 (2012).

38. Fritsch, M. J. et al. Proteomic identification of novel secreted antibacterial toxins of the Serratia marcescens type VI secretion system. Mol. Cell. Proteom.: MCP 12, 2735-2749 (2013).

39. Zhang, W. et al. A type VI secretion system regulated by OmpR in Yersinia pseudotuberculosis functions to maintain intracellular $\mathrm{pH}$ homeostasis. Environ. Microbiol. 15, 557-569 (2013).

40. Si, M. et al. Functional characterization of a mycothiol peroxidase in Corynebacterium glutamicum that uses both mycoredoxin and thioredoxin reducing systems in the response to oxidative stress. Biochem. J 469, 45-57 (2015).

41. Zhang, L. et al. The catabolite repressor/activator Cra is a bridge connecting carbon metabolism and host colonization in the plant drought resistancepromoting bacterium Pantoea alhagi LTYR-11Z. Appl. Environ. Microbiol. 84, e00054-18 (2018).

42. Jiang, Y. et al. Multigene editing in the Escherichia coli genome via the CRISPR-Cas9 system. Appl. Environ. Microbiol. 81, 2506-2514 (2015).

43. Shen, X. et al. Targeting eEF1A by a Legionella pneumophila effector leads to inhibition of protein synthesis and induction of host stress response. Cell Microbiol 11, 911-926 (2009).

44. Ouellette, S. P., Karimova, G., Davi, M. \& Ladant, D. Analysis of membrane protein interactions with a bacterial adenylate cyclase-based two-hybrid (BACTH) technique. Curr. Protoc. Mol. Biol. 118, 2012 21-20 1224 (2017).

45. Karimova, G., Pidoux, J., Ullmann, A. \& Ladant, D. A bacterial two-hybrid system based on a reconstituted signal transduction pathway. Proc. Natl Acad. Sci. USA 95, 5752-5756 (1998).

46. $\mathrm{Xu}, \mathrm{S}$. et al. FliS modulates FlgM activity by acting as a non-canonical chaperone to control late flagellar gene expression, motility and biofilm formation in Yersinia pseudotuberculosis. Environ. Microbiol. 16, 1090-1104 (2014).

47. $\mathrm{Xu}, \mathrm{L}$. et al. Inhibition of host vacuolar $\mathrm{H}+$-ATPase activity by a Legionella pneumophila effector. PLoS Pathog 6, e1000822 (2010).

48. Ma, L. S., Hachani, A., Lin, J. S., Filloux, A. \& Lai, E. M. Agrobacterium tumefaciens deploys a superfamily of type VI secretion DNase effectors as weapons for interbacterial competition in planta. Cell Host Microbe 16, 94-104 (2014).
49. Pissaridou, P. et al. The Pseudomonas aeruginosa T6SS-VgrG1b spike is topped by a PAAR protein eliciting DNA damage to bacterial competitors. Proc. Natl Acad. Sci. USA 115, 12519-12524 (2018).

50. Wang, T. et al. A type VI secretion system delivers a cell wall amidase to target bacterial competitors. Mol. Microbiol. 114, 308-321 (2020).

51. Guo, Y. et al. RalR (a DNase) and RalA (a small RNA) form a type I toxin-antitoxin system in Escherichia coli. Nucleic Acids Res 42, 6448-6462 (2014).

52. Miller, R. G., Tate, C. R. \& Mallinson, E. T. Improved XLT4 agar: small addition of peptone to promote stronger production of hydrogen-sulfide by Salmonellae. J. Food Prot 58, 115-119 (1995).

\section{Acknowledgements}

This work was supported by the grant of National Key R\&D Program of China (2018YFA0901200 to X.S. and T.G.D.), the National Natural Science Foundation of China (31670053 and 31725003 to X.S., 31970114 and 31671292 to Y.W.), the Open Project Program of the State Key Laboratory of Pathogen and Biosecurity (SKLPBS1825 to X.S.). L.X. is supported by China Postdoctoral Science Foundation (2018M631201) and Shaanxi Postdoctoral Science Foundation (2018BSHTDZZ20). We thank Dr. ZhaoQing Luo at Purdue University for valuable discussions and critical reading of the manuscript, Dr. Sheng Yang at Institute of Plant Physiology and Ecology, Chinese Academy of Sciences, and Dr. Quanjiang Ji at Shanghai Tech University for providing the CRISPR-Cas9 genome editing System, and Dr. Xiaodong Xu and Hao Nan at Northwest A\&F University for advice and technical assistance. We also thank the Teaching and Research Core Facility at College of Life Science (Min Duan, Ningjuan Fan, Xiyan Chen and Hui Duan), and Life Science Research Core Services, NWAFU (Luqi Li) for technical support.

\section{Author contributions}

L.S., J.P., Y.W., and X.S. conceived the study and designed experiments. Unless otherwise specified, L.S., J.P., and Y.Y. performed all of the experiments and conducted data analysis. L.S., J.P., Z.Z., and R.C. performed bacteria competition assays and data analysis. L.S., J.P., Y.Y., Z.Z., and R.C. generated strains, performed bacterial two-hybrid experimental and GST pull-down assays. Y.Y., Z.Z., R.C., S.J., C.Y., and L.S. performed protein expression and purification, and nuclease assay experiments. L.S., J.P., R.C., and C.Y. performed the confocal microscopy work and flow cytometry analysis. L.S., J.P., Z.W., and L.X. performed bioinformatics analysis. L.S., J.P., Y.Y., T.G.D., Y.W., and X.S. analyzed data and wrote the manuscript. All authors read and approved the final version of the paper.

\section{Competing interests}

The authors declare no competing interests.

\section{Additional information}

Supplementary information is available for this paper at https://doi.org/10.1038/s41467020-20726-8.

\section{Correspondence and requests for materials should be addressed to Y.W. or X.S}

Peer review information Nature Communications thanks the anonymous reviewers for their contribution to the peer review of this work. Peer reviewer reports are available.

Reprints and permission information is available at http://www.nature.com/reprints

Publisher's note Springer Nature remains neutral with regard to jurisdictional claims in published maps and institutional affiliations.

(c) (i) Open Access This article is licensed under a Creative Commons BY Attribution 4.0 International License, which permits use, sharing adaptation, distribution and reproduction in any medium or format, as long as you give appropriate credit to the original author(s) and the source, provide a link to the Creative Commons license, and indicate if changes were made. The images or other third party material in this article are included in the article's Creative Commons license, unless indicated otherwise in a credit line to the material. If material is not included in the article's Creative Commons license and your intended use is not permitted by statutory regulation or exceeds the permitted use, you will need to obtain permission directly from the copyright holder. To view a copy of this license, visit http://creativecommons.org/ licenses/by/4.0/.

(c) The Author(s) 2021 